\title{
Reliability-based stability analysis considering GCL shear strength variability
}

\author{
J. S. McCartney ${ }^{1}$, J. G. Zornberg ${ }^{2}$, R. H. Swan $\mathrm{Jr}^{3}$ and R. B. Gilbert ${ }^{4}$ \\ ${ }^{1}$ Graduate Student, The University of Texas at Austin, Civil Engineering Department-GEO, \\ 1 University Station C1792, Austin, TX 78712-0280, USA, Telephone: + 15122323595 , \\ Telefax: + 1512471 6548,E-mail: jmccartney@mail.utexas.edu \\ ${ }^{2}$ Clyde E. Lee Assistant Professor, The University of Texas at Austin, Civil Engineering \\ Department-GEO, 1 University Station C1792 Austin, TX 78712-0280, USA, \\ Telephone: + 1512232 3595, Telefax: +1512471 6548,E-mail: zornberg@mail.utexas.edu \\ ${ }^{3}$ President and CEO, SGI Testing Services, 4405 International Boulevard, Suite-B117, Norcross, \\ GA 30093, USA, Telephone: + 1866 SGI LAB1, Telefax: + 14047059300 , \\ E-mail:Testing@interactionspecialists.com \\ ${ }^{4}$ Associate Professor, The University of Texas at Austin, Civil Engineering Department-GEO, \\ 1 University Station C1792 Austin, TX 78712-0280, USA, Telephone: + 15122323688 , \\ Telefax: + 1512471 6548,E-mail: bob_gilbert@mail.utexas.edu
}

Received 28 December 2002, revised 4 April 2004, accepted 5 April 2004

\begin{abstract}
The impact of different levels of uncertainty in geosynthetic clay liner (GCL) shear strength on landfill stability is evaluated in this study. The uncertainty in shear strength of the interface governing landfill stability is defined using statistical parameters obtained from a significant database of GCL internal and GCL-geomembrane interface large-scale direct shear tests. Uncertainty in GCL shear strength arises from material variability within a single product type and between different product types. For a given product type, uncertainty arises from material differences among specimens from the same manufacturing lot as well as among specimens from different manufacturing lots. In addition, uncertainty was observed to arise from differences in test procedures such as hydration, consolidation and shear displacement rate. A framework for incorporating the observed laboratory shear strength variability into realistic field applications is presented. Reliability-based stability analyses were used to assess the impact of uncertainty in laboratory GCL shear strength test results on conventional design methodologies. Specifically, the impact of uncertainty on the relationships between the conventional safety factor and the probability of failure is assessed. Owing to the high shear strength variability observed in the database, high probability of failure values were found to correspond to safety factors typically used in geotechnical practice.
\end{abstract}

KEYWORDS: Geosynthetics, Design, GCL internal/interface shear strength, Quality assurance, Reliability-based stability analysis

REFERENCE: McCartney, J. S., Zornberg, J. G., Swan, R. H. Jr \& Gilbert, R. B. (2004). Reliability-based stability analysis considering GCL shear strength variability. Geosynthetics International, 11, No. 3, 212-232

\section{INTRODUCTION}

A large database, referred to herein as the GCLSS database, was assembled using 414 GCL internal and 427 GCL-geomembrane (GM) interface large-scale ( $305 \mathrm{~mm}$ by $305 \mathrm{~mm}$ ) direct shear tests. The tests were conducted between 1992 and 2003 by a single independent laboratory using test procedures consistent with ASTM D6243. Shear strength results were obtained for a wide range of GCL types (unreinforced, needlepunched, thermal-bonded and stitch-bonded), GM types [high density polyethylene (HDPE), very low density polyethylene (VLDPE), linear low density polyethylene (LLDPE) and polyvinyl chloride (PVC) polymers and textured or smooth surfaces], normal stresses $\left(\sigma_{\mathrm{n}}\right.$ from $2.4 \mathrm{kPa}$ to $2759 \mathrm{kPa}$ for internal testing, $\sigma_{\mathrm{n}}$ from $2.4 \mathrm{kPa}$ to $965 \mathrm{kPa}$ for interface testing), conditioning procedures (hydration times, $t_{\mathrm{h}}$, from 0 to $168 \mathrm{~h}$ and consolidation times, $t_{\mathrm{c}}$, from 0 to $48 \mathrm{~h}$ ), and shear displacement rates (shearing duration from $1.25 \mathrm{~h}$ to 35 days). Analysis of the effect of different variables on GCL internal and interface shear strength, as well as investigation of the sources of internal and interface shear strength variability, is reported elsewhere (McCartney et al. 2002a, 
2000b). However, the relatively high GCL internal and GCL-GM interface shear strength variability noted in the data accentuated the need to evaluate the impact of such variability in the design of engineering systems involving GCLs. The main focus of this study is on the GCL internal and GCL-textured HDPE GM interface shear strength data for a single needle-punched, nonthermally locked GCL, hereafter referred to as GCL A. However, data from other GCLs (needle-punched with thermal locking, stitch-bonded, and unreinforced) and other GMs [smooth and textured LLDPE, very flexible polyethylene (VFPE), and PVC] will also be assessed. Only the woven carrier geotextile side of the GCL was tested for interface shear strength. The GCLSS database is sufficient in scale to provide statistical characterization of the GCL internal and interface shear strength parameters and to develop probabilistic distributions for parameters needed for implementation of reliabilitybased analyses.

The objectives of this paper are:

- to provide statistical characterization of the sources of GCL internal and GCL-GM interface laboratory shear strength;

- to develop relationships between the safety factor and the probability of failure for slopes including a GCL interface;

- to evaluate the impact of GCL shear strength variability arising from different sources of uncertainty on the conventional safety factor used in design.

\section{CONVENTIONAL AND RELIABILITY FRAMEWORKS FOR QUANTIFYING UNCERTAINTY}

The conventional definition of the safety factor FS is used in this study, which can generically be defined as:

$$
\mathrm{FS}=\frac{\text { Available shear strength }}{\text { Shear stress required for equilibrium }}
$$

This definition is consistent with conventional limit equilibrium analysis, for which extensive experience has evolved for the analysis of reinforced and unreinforced slopes (Zornberg et al. 1998). The use of Equation 1 for an unreinforced veneer, such as that shown in Figure 1, leads to the classic expression for the safety factor:

$$
\mathrm{FS}=\frac{c}{\gamma T \sin \psi}+\frac{\tan \phi}{\tan \psi}
$$

where $c$ is the soil cohesion intercept, $\tan \phi$ is the tangent of the soil friction angle, $\psi$ is the slope inclination, $T$ is the veneer thickness, and $\gamma$ is the total soil unit weight. It should be noted that the FS of an unreinforced veneer depends on the veneer geometry (inclination, thickness) and on the material properties (GCL internal and interface shear strength parameters, soil unit weight), all of which may be considered random variables. In conventional design methodologies, uncertainty in GCL shear strength is managed by calculating the available shear strength using the mean values of the shear

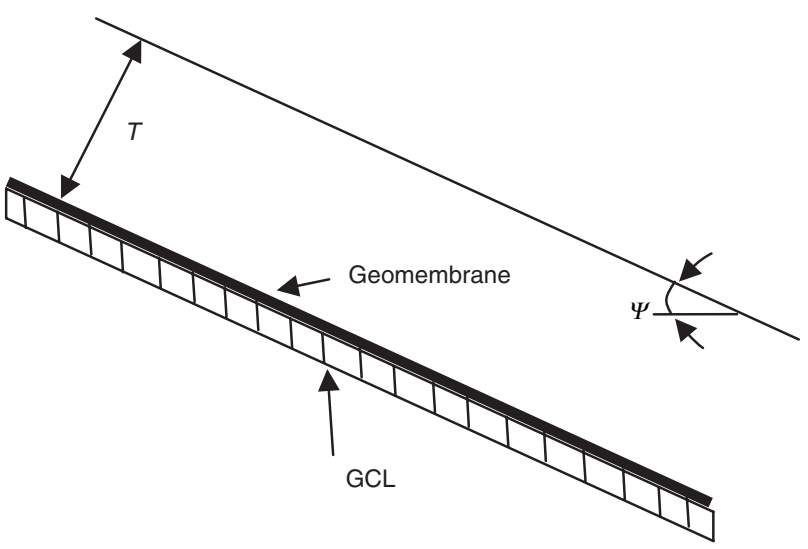

Figure 1. Definition of variables for veneer stability analysis

strength parameters $c$ and $\tan \phi$, and reducing the maximum applied shear stress using the FS in Equation 1. However, as will be discussed, accounting for the variability in shear strength parameters may be relevant, particularly if non-project-specific information is used. Difficulties arise in conventional design methodologies as the choice of the FS is typically based on experience and judgement, without an objective framework to assess the impact of different sources of uncertainty on the stability of the system.

Reliability-based analysis provides quantification of the safety of a system by examining the variability of the relevant parameters as well as their interdependence (correlation). The reliability index is a simple measure used to quantify the level of reliability of a given design as a function of the selected FS and the uncertainty of relevant parameters. The reliability index $\beta$ is defined as follows (Ang and Tang 1984):

$$
\beta=\frac{\mu_{\text {Strength }}-\mu_{\text {Stress }}}{\sqrt{s_{\text {Strength }}^{2}+s_{\text {Stress }}^{2}}}
$$

where $\mu_{\text {Strength }}$ is the expected or mean value for the available shear strength, $\mu_{\text {Stress }}$ is the expected or mean value for the shear stress mobilized in the slope, and $s_{\text {Strength }}$ and $s_{\text {Stress }}$ are the standard deviations characterizing the uncertainty in the available shear strength and the mobilized shear stress, respectively. The reliability index increases as the likelihood of slope failure decreases and the level of safety increases. The probability of failure $p_{\mathrm{f}}$ of the slope can be obtained approximately from the reliability index through the following relationship:

$$
p_{\mathrm{f}} \cong \Phi(-\beta)
$$

where $\Phi$ is the standard normal probability distribution (Ang and Tang 1975). In this paper, $p_{\mathrm{f}}$ is designated as the probability of the event that the available shear strength is less than the shear stress required for equilibrium (i.e. $\mathrm{FS}<1$ ). This does not necessarily mean that collapse of the system occurs only when the available shear strength is exceeded. The standard deviations in the shear strength and the mobilized shear stress can be conveniently expressed as a fraction 
of the mean values using coefficients of variation as follows:

$$
\beta=\frac{\mu_{\text {Strength }}-\mu_{\text {Stress }}}{\sqrt{\delta_{\text {Strength }}^{2} \mu_{\text {Strength }}^{2}+\delta_{\text {Stress }}^{2} \mu_{\text {Stress }}^{2}}}
$$

where $\delta_{\text {Strength }}$ is the coefficient of variation of the strength, which is the standard deviation divided by the mean, and $\delta_{\text {Stress }}$ symbolises the coefficient of variation of the mobilized stress. The coefficient of variation of the mobilized shear stress in Equation $5, \delta_{\text {Stress }}$, reflects the uncertainty in slope angle, density of materials loading the slope, and other external forces that could be applied on the slope. In static analyses, which are the focus of this paper, the coefficient of variation, $\delta_{\text {Stress }}$, is expected to be small.

The reliability index is related to the conventional FS, as the allowable value for the expected mobilized stress is obtained by reducing the expected available shear strength by the FS:

$$
\mu_{\text {Stress }} \leq \frac{\mu_{\text {Strength }}}{\text { FS }}
$$

Therefore the reliability index in Equation 5 can be simplified using Equation 6 by relating the reliability index to the FS and the coefficients of variation for the available shear strength and the mobilized shear stress, as follows:

$$
\begin{aligned}
& \beta=\frac{\mu_{\text {Strength }}-\mu_{\text {Strength }} / \mathrm{FS}}{\sqrt{\delta_{\text {Strength }}^{2} \mu_{\text {Strength }}^{2}+\delta_{\text {Stress }}^{2}\left(\mu_{\text {Strength }} / \mathrm{FS}\right)^{2}}} \\
& \beta=\frac{1-1 / \mathrm{FS}}{\sqrt{\delta_{\text {Strength }}^{2}+\delta_{\text {Stress }}^{2} / \mathrm{FS}^{2}}}
\end{aligned}
$$

\section{VARIABILITY OF SHEAR STRENGTH PARAMETERS}

\subsection{Sources of uncertainty in GCL shear strength}

The overall coefficient of variation for the available shear strength in Equation $8, \delta_{\text {Strength }}$, includes the following sources of uncertainty: (1) uncertainty in the shear strength from laboratory testing for the GCL, referred to as $\delta_{\text {Strength, }}^{\mathrm{Lab}}$, and (2) uncertainty in the use of laboratorymeasured shear strengths to reflect the available shear strength that can be mobilized in the field, referred to as $\Omega_{\text {Strength }}^{\mathrm{Mod}}$. If it is assumed that there is no systematic bias in the measured shear strength (i.e. specimen conditioning procedures are representative of field conditions), then the total uncertainty in the available shear strength in the field, $\delta_{\text {Strength }}$, is

$$
\delta_{\text {Strength }}=\sqrt{\left(\delta_{\text {Strength }}^{\text {Lab }}\right)^{2}+\left(\Omega_{\text {Strength }}^{\text {Model }}\right)^{2}}
$$

Evaluation of the laboratory GCL internal and GCLGM interface shear strength results in the GCLSS database indicates that $\delta_{\text {Strength }}^{\mathrm{Lab}}$ arises from three main sources, summarized in Figure 2:

(1) differences in laboratory procedures and equipment;

(2) material variability; and

(3) variations in specimen conditioning procedures (i.e. hydration time $t_{\mathrm{h}}$, consolidation time $t_{\mathrm{c}}$, and shear displacement rate SDR).

In turn, three main sources of material variability can be identified (McCartney et al. 2002b):

(2-i) intra-product shear strength variability of a single type of GCL (or GCL-GM combination) for the case in which the GCL (or the GCL and GM) specimens are obtained from a single manufacturing lot;

(2-ii) overall intra-product shear strength variability of a single type of GCL (or GCL-GM combination) for the case in which the GCL (or the GCL and GM) specimens are obtained from different manufacturing lots; and

(2-iii) inter-product variability among different types of GCL (or GCL-GM combinations).

When Source (2-i) is isolated (i.e. the effects of Sources (1) and (3) are held constant), this source is referred to as the shear strength repeatability. That is, the laboratory

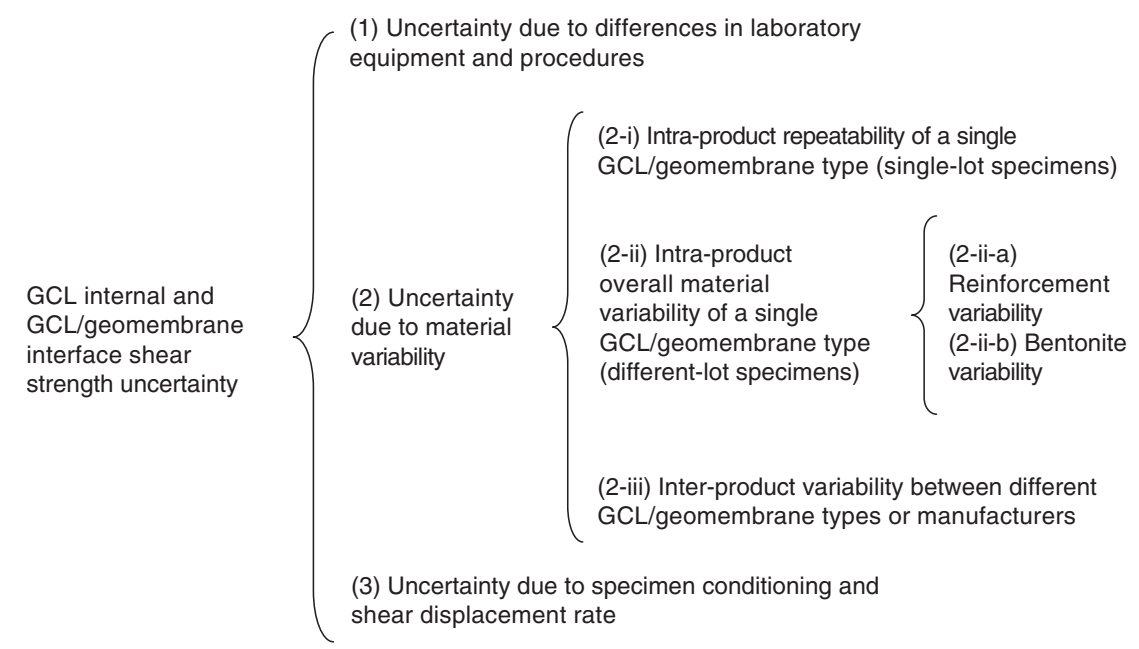

Figure 2. Classification of the sources of variability in GCL internal and GCL-GM interface shear strength 
GCL shear strength variability arises from testing nearly identical, same-lot specimens while controlling all variables that may affect the GCL's strength. It should be noted that different GCL types have different internal reinforcement types and carrier geotextile surface treatments, whereas different GMs have different polymer types and surface texturing. Accordingly, the overall intra-product variability of a single GCL from different manufacturing lots can arise from:

(2-ii-a) variability in internal GCL reinforcement (or in GCL-GM interlocking connections); and

(2-ii-b) variability in bentonite composition (or in the amount of bentonite extruded from the GCL into the GM interface).

Stability analyses of systems including a GCL can be conducted using GCL shear strength information obtained from a database to define $\delta_{\text {Strength }}^{\mathrm{Lab}}$. However, shear strength parameters should be selected to account appropriately for the different sources of uncertainty. Among the sources of uncertainty in shear strength identified in Figure 2, Source (1) is not evaluated in this study, as the shear strength information in the GCLSS database was obtained from a single laboratory using consistent testing procedures. Source (2-i) should be accounted for when the actual type of GCL to be used during construction has been selected. Also, Source (2-i) should be accounted for when testing the overall accuracy and consistency of the testing program. Source (2-ii) should be accounted for when the actual type of GCL to be used during construction has been selected, but several GCL manufacturing lots are expected to be used in design. Engineering applications involving GCLs may incorporate one or more GCL manufacturing lots in a single slope, so designers should differentiate whether the variability in shear strength arises from Source (2-i) or from Source (2-ii). Source (2-iii) should be accounted for when the type of GCL to be used during construction has not been selected. Finally, Source (3) should be accounted for when there is uncertainty regarding the GCL specimen conditioning representative of field conditions (e.g. if the conditions in the field are uncertain or have not been defined).

In the following sections, GCL internal and interface shear strength data will be assessed to develop a framework for quantifying $\delta_{\text {Strength }}$ for use in reliability-based stability analyses. Section 3.2 presents a quantification of the laboratory shear strength variability arising from the different sources of uncertainty using data sets from the GCLSS database. Section 3.3 presents a framework for isolating the shear strength variability arising from the different sources of uncertainty to define representative values of $\delta_{\text {Strength }}^{\text {Lab }}$ for different design scenarios. Section 3.4 provides representative values of $\Omega_{\mathrm{Strength}}^{\text {Model }}$ based on past evaluations of the relationship between laboratory and back-calculated stress-strength results.

\subsection{Laboratory shear strength variability characterization}

3.2.1. Sets of tests used for characterization of shear strength variability

GCL internal and interface shear strength information in the GCLSS database is grouped in this study into eight sets to evaluate shear strength variability arising from sources of uncertainty (2-i), (2-ii), (2-iii) and (3). This section initially focuses on Source (2-i) as obtained from quantification of the single-lot repeatability specific to the GCL A product line (tested for internal and interfacial shear strength). Next, the effects of isolating Source (2-ii) for GCL A and the combined effect of Sources (2-ii) and (3) for GCL A are evaluated. Finally, the combined effect of Source (2-iii) for all GCLs in the database is evaluated. This information will be used to aid in the definition of $\delta_{\text {Strength }}^{\text {Lab }}$ for different situations expected in design and quality assurance testing programs.

Internal and interface test results obtained using the same GCL and GM types (from the same lots) and the same conditioning procedures are used to characterize uncertainty Source (2-i). Internal and interface test results obtained using the same GCL and GM types (from different lots) and the same conditioning procedures are used to characterize uncertainty Source (2ii). Internal and interface test results obtained using the same GCL type (from different lots) and different conditioning procedures are used to characterize the combined effect of uncertainty Sources (2-ii) and (3). Finally, internal and interface test results obtained using all of the different GCL types and different conditioning procedures are used to characterize the combined effect of uncertainty Sources (2-iii) and (3). Table 1 summarizes the numbers of test results, conditioning procedures, and normal stress $\left(\sigma_{\mathrm{n}}\right)$ ranges for the eight sets. They are:

- Set 1: involves a total of nine test results from GCL specimens obtained from the same manufacturing lot. Specifically, three needle-punched GCL A internal $\tau_{\mathrm{p}}$ envelopes were defined using three levels of $\sigma_{\mathrm{n}}(48.3$, 213.7 and $386.1 \mathrm{kPa})$. The same conditioning procedures (i.e. same $t_{\mathrm{h}}, t_{\mathrm{c}}$ and SDR; see Table 1) were used in all tests. Set 1 allows statistical characterization of internal shear strength parameters for the case in which uncertainty in the internal shear strength arises from Source (2-i).

- Set 2: involves a total of 10 test results from GCL and GM specimens obtained from the same manufacturing lot. Specifically, two GCL A-GM interface $\tau_{\mathrm{p}}$ envelopes were defined using five levels of $\sigma_{\mathrm{n}}(9.6$, $47.9,95.8,191.5$ and $287 \mathrm{kPa}$ ). The GM is a textured HDPE GM. The same conditioning procedures (see Table 1) were used in all tests. Set 2 allows statistical characterization of interface shear strength parameters for the case in which uncertainty in the GCL interface shear strength arises from Source (2-i).

- Set 3: involves a total of 141 test results from GCL specimens obtained from different manufacturing lots. 
Table 1. Sets of GCL internal and GCL/textured HDPE GM interface shear strength parameters used in reliability analyses

\begin{tabular}{|c|c|c|c|c|c|c|c|}
\hline \multirow{2}{*}{$\begin{array}{c}\text { Set } \\
\text { number }\end{array}$} & \multirow[t]{2}{*}{ Set description } & \multirow[t]{2}{*}{ Variability description } & \multirow{2}{*}{$\begin{array}{l}\text { Number } \\
\text { of tests }\end{array}$} & \multicolumn{4}{|c|}{ Test conditions } \\
\hline & & & & $\begin{array}{l}t_{\mathrm{h}} \\
(\mathrm{h})\end{array}$ & $\begin{array}{c}t_{\mathrm{c}} \\
(\mathrm{h})\end{array}$ & $\begin{array}{c}\mathrm{SDR} \\
(\mathrm{mm} / \mathrm{min})\end{array}$ & $\begin{array}{c}\sigma_{\mathrm{n}} \text { range } \\
(\mathrm{kPa})\end{array}$ \\
\hline 1 & GCL A internal & $\begin{array}{l}\text { Intra-product repeatability (same-lot), } \\
\text { constant conditioning procedures }\end{array}$ & 9 & 24 & 0 & 0.5 & $63-386$ \\
\hline 2 & GCL A - textured HDPE GM interfaces & $\begin{array}{l}\text { Intra-product repeatability (same-lot), } \\
\text { constant conditioning procedures }\end{array}$ & 10 & 24 & 0 & 0.2 & $9.6-287$ \\
\hline 3 & GCL A internal & $\begin{array}{l}\text { Intra-product (different-lot), constant } \\
\text { conditioning procedures }\end{array}$ & 141 & 168 & 48 & 0.1 & $35-310$ \\
\hline 4 & GCL A - textured HPDE GM interfaces & $\begin{array}{l}\text { Intra-product (different-lot), constant } \\
\text { conditioning procedures }\end{array}$ & 162 & 168 & 48 & 0.1 & $35-310$ \\
\hline 5 & GCL A internal & $\begin{array}{l}\text { Intra-product (different-lot) different } \\
\text { conditioning procedures }\end{array}$ & 133 & $0-168$ & $0-24$ & $0.05-1.0$ & $2.4-100$ \\
\hline 6 & GCL A - textured HDPE GM interfaces & $\begin{array}{l}\text { Intra-product (different-lot) different } \\
\text { conditioning procedures }\end{array}$ & 252 & $0-168$ & $0-48$ & $0.01-1.0$ & $6.9-689$ \\
\hline 7 & All GCL ${ }^{(a)}$ internal & $\begin{array}{l}\text { Inter-product, different conditioning } \\
\text { procedures }\end{array}$ & 230 & $0-168$ & $0-24$ & $0.05-1.0$ & $2.4-100$ \\
\hline 8 & All $\mathrm{GCL}^{(\mathrm{a})}-\mathrm{GM}^{\text {(b) }}$ interfaces & $\begin{array}{l}\text { Inter-product, different conditioning } \\
\text { procedures }\end{array}$ & 424 & $0-168$ & $0-48$ & $0.01-1.0$ & $6.9-689$ \\
\hline
\end{tabular}

(a) Needle-punched with and without thermal-locking, stitch-bonded unreinforced

(b) Smooth and textured HDPE, LLDPE, VFPE, PVC

Specifically, 34 needle-punched GCL A internal $\tau_{\mathrm{p}}$ envelopes were defined using three levels of $\sigma_{\mathrm{n}}(34.5$, 137.9 and $310.3 \mathrm{kPa}$ ). The same conditioning procedures (see Table 1) were used in all tests. Set 3 allows statistical characterization of internal shear strength parameters for the case in which uncertainty in the internal shear strength arises from Source (2-ii).

- Set 4: involves a total of 162 test results from GCL and GM specimens obtained from different manufacturing lots. Specifically, 41 GCL A-GM interface $\tau_{\mathrm{p}}$ envelopes were defined using three $\sigma_{\mathrm{n}}$ values (34.5, 137.9 and $310.3 \mathrm{kPa}$ ). The GM is a textured HDPE GM. The same conditioning procedures (see Table 1) were used in all tests. Set 4 allows statistical characterization of interface shear strength parameters for the case in which uncertainty in the GCL interface shear strength arises from Source (2-ii).

- Set 5: involves a total of 137 test results from GCL specimens obtained from different manufacturing lots. Specifically, eight internal $\tau_{\mathrm{p}}$ envelopes were defined using the same GCL type (GCL A), but each envelope was obtained using different conditioning procedures (see Table 1). Also, 52 additional tests are included in the analysis that did not belong to complete failure envelopes (i.e. tests with given conditioning procedures were tested at one $\sigma_{\mathrm{n}}$ value only). Although the GCLSS database includes 270 test results for GCL A, the behavior of GCL shear strength is observed to change with $\sigma_{\mathrm{n}}$ (McCartney et al. 2002b). Accordingly, only the shear strength values below $\sigma_{\mathrm{n}}=100 \mathrm{kPa}$ were selected. Set 5 allows statistical characterization of shear strength parameters for the situation in which uncertainty in the GCL internal shear strength arises from Sources (2-ii) and (3).

- Set 6: involves a total of 252 test results from GCL and GM specimens obtained from different manufacturing lots. Specifically, 12 GCL A-GM interface $\tau_{\mathrm{p}}$ envelopes were defined using the same GCL type
(GCL A) and different conditioning procedures (see Table 1). As GCL-GM interface shear strength does not change appreciably with $\sigma_{\mathrm{n}}$, shear strength values corresponding to $\sigma_{\mathrm{n}}$ ranging from 2.4 to $689 \mathrm{kPa}$ were included. The GM used in all failure envelopes is always a textured HDPE product. Set 6 allows statistical characterization of shear strength parameters for the case in which uncertainty in the GCL interface shear strength arises from Sources (2-ii) and (3).

- Set 7: involves a total of 230 test results from GCL specimens obtained from different manufacturing lots, which were not categorised into failure envelopes for this analysis. This set encompasses results for GCLs with different reinforcement types (needle-punched with and without thermal locking, stitch-bonded, and unreinforced). As the behavior of GCL shear strength changes with $\sigma_{\mathrm{n}}$, only the shear strength values below $\sigma_{\mathrm{n}}=100 \mathrm{kPa}$ were selected. Set 7 allows statistical characterization of shear strength parameters for the situation in which uncertainty in the GCL internal shear strength arises from Sources (2-iii) and (3).

- Set 8: involves a total of 424 test results from GCL and GM specimens obtained from different manufacturing lots, which were not categorised into failure envelopes for this analysis. This set encompasses results for the interface between GCLs with different reinforcement types (needle-punched with and without thermal locking, stitch-bonded, unreinforced) and GMs with different surface finishes (textured and smooth) and polymers (HDPE, VFLPE, LLDPE, PVC). Three outliers were removed because of unrepresentative testing conditions. As GCL-GM interface shear strength does not change appreciably with $\sigma_{\mathrm{n}}$, shear strength values corresponding to $\sigma_{\mathrm{n}}$ ranging from 2.4 to $689 \mathrm{kPa}$ were included. Set 6 allows statistical characterization of shear strength 
parameters for the case in which uncertainty in the GCL interface shear strength arises from Sources (2iii) and (3).

The GCL shear strength variability arising from the different sources of uncertainty is quantified using linear regression. The shear strength variability for Sets $1-6$ is first characterized by defining individual failure envelopes within each of the different sets based on groupings of GCL specimens from the same manufacturing lots (i.e. in Sets 1-4) and specimens tested with similar conditioning procedures (i.e. in Sets 5 and 6). For each set, $\delta_{\text {Strength }}^{\mathrm{Lab}}$ is quantified by calculating the coefficient of variation for the cohesion intercept, $\delta_{c}$, and the tangent of the friction angle, $\delta_{\tan \phi}$, for the group of individual failure envelopes. In addition, the shear strength variability in Sets $1-8$ is characterized by defining a global failure envelope for each set. For each set, $\delta_{\text {Strength }}^{\mathrm{Lab}}$ is defined from the outputs of a linear regression analysis for different values of $\sigma_{\mathrm{n}}$. Although characterization of the variability using individual failure envelopes is more appropriate if the repeatability [Source (2-i)] is small relative to the other sources, it is more complicated than characterizing the variability using a global failure envelope. Both approaches have limitations in incorporating the shear strength variability into $\delta_{\text {Strength. }}^{\text {Lab }}$. Specifically, the accuracy of the linear regression analyses depends on the suitability of the linear model to fit the data and the suitability of extrapolating shear strength variability observed at discrete $\sigma_{\mathrm{n}}$ values to the range of $\sigma_{\mathrm{n}}$ in the envelopes.

3.2.2. Shear strength variability characterization by an individual failure envelope approach

Table 2 presents the shear strength parameters for the three GCL internal envelopes used in Set 1 and the parameters for the two GCL-GM interface shear strength envelopes used in Set 2, along with mean, standard deviation, and the coefficients of variation for the cohesion intercept $\delta_{c}$ and the tangent of the friction angle $\delta_{\tan \phi}$ for Sets 1 and 2. Figures 3a and 3b show the peak GCL A internal and interface shear strength values for Sets 1 and 2 respectively. The failure envelopes are defined using the expected (mean) value of the shear strength parameters [i.e. $\mu(\tan \phi)$ and $\mu(c)$ ] shown in the figures. Owing to the limited number of failure envelopes in Sets 1 and 2, the statistical information should be used with caution. Nonetheless, it is reasonable to assume

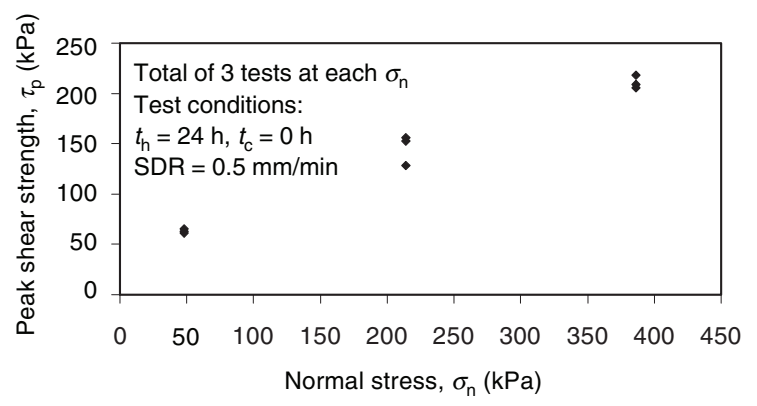

(a)

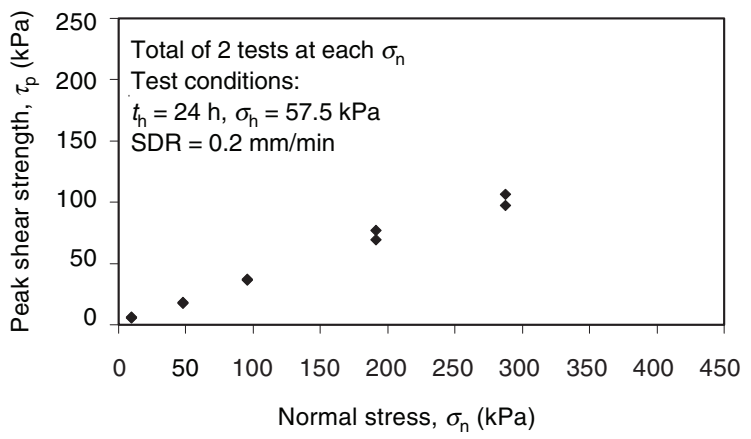

(b)

Figure 3. GCL A shear strength repeatability (intra-product, same-lot, same conditioning procedures): (a) GCL A internal peak shear strength envelope (Set 1); (b) peak shear strength envelope for interface between GCL $A$ and a textured HDPE GM (Set 2)

that, for the same constant conditions and nearly identical GCL specimens, the shear strength variability can be characterized by the coefficients of variation in Table 2.

Table 3 presents the shear strength parameters for the 47 GCL internal envelopes used in Set 3 and the parameters for the 54 GCL-GM interface shear strength envelopes used in Set 4. Table 3 also shows the mean, standard deviation, $\delta_{c}$ and $\delta_{\tan \phi}$ values, and the correlation coefficient $\rho(c, \tan \phi)$ between $c$ and $\tan \phi$ for both sets. The frequency density distributions for $c$ and $\tan \phi$ representing the peak shear strength for Set 3 are presented in Figures $4 \mathrm{a}$ and $4 \mathrm{~b}$, and Figures $4 \mathrm{c}$ and $4 \mathrm{~d}$ show the same information for Set 4. Visual interpretation of the frequency density distributions shown in the figures indicates that a log-normal distribution is a reasonable model for $c$ and $\tan \phi$ for both the

Table 2. Analysis of individual GCL internal and interface failure envelopes to find $\delta_{c}$ and $\delta_{\tan \phi}$ for Sets 1 and 2

\begin{tabular}{|c|c|c|c|c|c|}
\hline $\begin{array}{c}\text { GCL A } \\
\text { Envelope number }\end{array}$ & $\begin{array}{c}c \\
(\mathrm{kPa})\end{array}$ & $\tan \phi$ & $\begin{array}{l}\text { GCL A-textured HDPE } \\
\text { GM Envelope number }\end{array}$ & $\begin{array}{c}c \\
(\mathrm{kPa})\end{array}$ & $\tan \phi$ \\
\hline $\begin{array}{l}\text { Set }(1-1) \\
\text { Set }(1-2) \\
\text { Set }(1-3)\end{array}$ & $\begin{array}{l}49.21 \\
48.16 \\
39.51\end{array}$ & $\begin{array}{l}0.43 \\
0.45 \\
0.43\end{array}$ & $\begin{array}{l}\text { Set }(2-1) \\
\text { Set }(2-2)\end{array}$ & $\begin{array}{l}1.32 \\
2.19\end{array}$ & $\begin{array}{l}0.37 \\
0.36\end{array}$ \\
\hline $\begin{array}{c}\text { Mean } \\
\text { Standard deviation } \\
\delta^{(\mathrm{a})}\end{array}$ & $\begin{array}{c}45.63 \\
5.32 \\
0.12\end{array}$ & $\begin{array}{l}0.44 \\
0.01 \\
0.03\end{array}$ & $\begin{array}{c}\text { Mean } \\
\text { Standard deviation } \\
\delta^{(\mathrm{a})}\end{array}$ & $\begin{array}{l}1.76 \\
0.61 \\
0.35\end{array}$ & $\begin{array}{l}0.36 \\
0.01 \\
0.03\end{array}$ \\
\hline
\end{tabular}

(a) Caution should be used due to limited data 
Table 3. Analysis of individual GCL internal and interface failure envelopes to find $\delta_{c}$ and $\delta_{\tan \phi}$ for Sets 3 and 4

\begin{tabular}{|c|c|c|c|c|c|}
\hline $\begin{array}{l}\text { GCL A Envelope } \\
\text { number }\end{array}$ & $\begin{array}{c}c \\
(\mathrm{kPa})\end{array}$ & $\tan \phi$ & $\begin{array}{l}\text { GCL A textured HDPE } \\
\text { GM Envelope number }\end{array}$ & $\begin{array}{c}c \\
(\mathrm{kPa})\end{array}$ & $\tan \phi$ \\
\hline $\begin{array}{l}\text { Set (3-1) } \\
\text { Set (3-2) } \\
\text { Set (3-3) } \\
\text { Set (3-4) } \\
\text { Set (3-5) } \\
\text { Set (3-6) } \\
\text { Set (3-7) } \\
\text { Set (3-8) } \\
\text { Set (3-9) } \\
\text { Set (3-10) } \\
\text { Set (3-11) } \\
\text { Set (3-12) } \\
\text { Set (3-13) } \\
\text { Set (3-14) } \\
\text { Set (3-15) } \\
\text { Set (3-16) } \\
\text { Set (3-17) } \\
\text { Set (3-18) } \\
\text { Set (3-19) } \\
\text { Set (3-20) } \\
\text { Set (3-21) } \\
\text { Set (3-22) } \\
\text { Set (3-23) } \\
\text { Set (3-24) } \\
\text { Set (3-25) } \\
\text { Set (3-26) } \\
\text { Set (3-27) } \\
\text { Set (3-28) } \\
\text { Set (3-29) } \\
\text { Set (3-30) } \\
\text { Set (3-31) } \\
\text { Set (3-32) } \\
\text { Set (3-33) } \\
\text { Set (3-34) } \\
\text { Set (3-35) } \\
\text { Set (3-36) } \\
\text { Set (3-37) } \\
\text { Set (3-38) } \\
\text { Set (3-39) } \\
\text { Set (3-40) } \\
\text { Set (3-41) } \\
\text { Set (3-42) } \\
\text { Set (3-43) } \\
\text { Set (3-44) } \\
\text { Set (3-45) } \\
\text { Set (3-46) } \\
\text { Set (3-47) }\end{array}$ & $\begin{array}{r}16.55 \\
27.78 \\
26.59 \\
38.81 \\
17.63 \\
27.29 \\
29.45 \\
30.63 \\
27.97 \\
18.62 \\
29.45 \\
36.25 \\
39.60 \\
45.41 \\
22.56 \\
44.82 \\
36.84 \\
24.72 \\
15.29 \\
15.21 \\
8.35 \\
11.17 \\
15.68 \\
12.69 \\
13.45 \\
17.98 \\
17.01 \\
24.47 \\
12.29 \\
16.50 \\
13.36 \\
13.69 \\
10.45 \\
37.13 \\
10.13 \\
8.77 \\
9.64 \\
16.92 \\
11.51 \\
11.01 \\
15.44 \\
23.95 \\
26.90 \\
7.89 \\
5.68 \\
16.99 \\
6.55\end{array}$ & $\begin{array}{l}0.48 \\
0.57 \\
0.49 \\
0.59 \\
0.69 \\
0.60 \\
0.55 \\
0.65 \\
0.47 \\
0.56 \\
0.56 \\
0.39 \\
0.40 \\
0.53 \\
0.65 \\
0.49 \\
0.48 \\
0.62 \\
0.43 \\
0.43 \\
0.40 \\
0.46 \\
0.43 \\
0.43 \\
0.48 \\
0.47 \\
0.43 \\
0.30 \\
0.50 \\
0.39 \\
0.43 \\
0.41 \\
0.44 \\
0.67 \\
0.45 \\
0.43 \\
0.39 \\
0.38 \\
0.47 \\
0.41 \\
0.41 \\
0.40 \\
0.31 \\
0.42 \\
0.42 \\
0.38 \\
0.41\end{array}$ & $\begin{array}{l}\text { Set }(4-1) \\
\text { Set }(4-2) \\
\text { Set }(4-3) \\
\text { Set }(4-4) \\
\text { Set }(4-5) \\
\text { Set }(4-6) \\
\text { Set }(4-7) \\
\text { Set }(4-8) \\
\text { Set }(4-9) \\
\text { Set }(4-10) \\
\text { Set }(4-11) \\
\text { Set }(4-12) \\
\text { Set }(4-13) \\
\text { Set }(4-14) \\
\text { Set }(4-15) \\
\text { Set }(4-16) \\
\text { Set }(4-17) \\
\text { Set }(4-18) \\
\text { Set }(4-19) \\
\text { Set }(4-20) \\
\text { Set }(4-21) \\
\text { Set }(4-22) \\
\text { Set }(4-23) \\
\text { Set }(4-24) \\
\text { Set }(4-25) \\
\text { Set }(4-26) \\
\text { Set }(4-27) \\
\text { Set }(4-28) \\
\text { Set }(4-29) \\
\text { Set }(4-30) \\
\text { Set }(4-31) \\
\text { Set }(4-32) \\
\text { Set }(4-33) \\
\text { Set } 4-34) \\
\text { Set }(4-35) \\
\text { Set }(4-36) \\
\text { Set }(4-37) \\
\text { Set }(4-38) \\
\text { Set }(4-39) \\
\text { Set }(4-40) \\
\text { Set }(4-41) \\
\text { Set }(4-42) \\
\text { Set }(4-43) \\
\text { Set }(4-44) \\
\text { Set }(4-45) \\
\text { Set }(4-46) \\
\text { Set }(4-47) \\
\text { Set }(4-48) \\
\text { Set }(4-49) \\
\text { Set }(4-50) \\
\text { Set }(4-51) \\
\text { Set }(4-52) \\
\text { Set }(4-53) \\
\text { Set }(4-54)\end{array}$ & $\begin{array}{r}4.92 \\
1.48 \\
7.29 \\
7.19 \\
5.12 \\
6.89 \\
5.32 \\
15.07 \\
12.12 \\
5.61 \\
2.07 \\
12.71 \\
0.98 \\
10.64 \\
12.31 \\
20.78 \\
3.55 \\
5.81 \\
6.89 \\
1.77 \\
1.40 \\
4.69 \\
4.97 \\
1.37 \\
4.95 \\
15.24 \\
6.47 \\
7.48 \\
4.29 \\
4.22 \\
3.42 \\
4.58 \\
11.46 \\
4.49 \\
4.31 \\
4.41 \\
4.51 \\
4.69 \\
4.82 \\
1.86 \\
10.19 \\
10.85 \\
0.91 \\
2.26 \\
7.10 \\
2.98 \\
6.30 \\
7.13 \\
6.84 \\
7.63 \\
3.80 \\
3.51 \\
2.78 \\
2.18\end{array}$ & $\begin{array}{l}0.38 \\
0.38 \\
0.29 \\
0.33 \\
0.30 \\
0.37 \\
0.49 \\
0.28 \\
0.30 \\
0.40 \\
0.37 \\
0.29 \\
0.38 \\
0.51 \\
0.44 \\
0.42 \\
0.43 \\
0.43 \\
0.37 \\
0.38 \\
0.46 \\
0.37 \\
0.37 \\
0.51 \\
0.38 \\
0.33 \\
0.34 \\
0.36 \\
0.39 \\
0.38 \\
0.40 \\
0.42 \\
0.34 \\
0.32 \\
0.36 \\
0.37 \\
0.38 \\
0.37 \\
0.33 \\
0.41 \\
0.36 \\
0.34 \\
0.42 \\
0.40 \\
0.39 \\
0.41 \\
0.34 \\
0.34 \\
0.32 \\
0.34 \\
0.41 \\
0.33 \\
0.35 \\
0.34\end{array}$ \\
\hline $\begin{array}{c}\text { Mean, } \mu \\
\text { Standard deviation, } s \\
\delta\end{array}$ & $\begin{array}{r}20.58 \\
10.59 \\
0.51\end{array}$ & $\begin{array}{l}0.47 \\
0.09 \\
0.20\end{array}$ & \multirow{2}{*}{$\begin{array}{c}\text { Mean, } \mu \\
\text { Standard deviation, } s \\
\delta \\
\rho(\tan \phi, c)\end{array}$} & $\begin{array}{l}6.05 \\
4.07 \\
0.67\end{array}$ & $\begin{array}{l}0.37 \\
0.05 \\
0.14\end{array}$ \\
\hline$\rho(\tan \phi, c)$ & & & & \multicolumn{2}{|c|}{-0.3} \\
\hline
\end{tabular}

Note: $t_{\mathrm{h}}=168 \mathrm{~h}, \sigma_{\mathrm{h}}=20.1 \mathrm{kPa}, t_{\mathrm{c}}=48 \mathrm{~h}, \mathrm{SDR}=0.1 \mathrm{~mm} / \mathrm{min}$

GCL internal and interface data. The functional interdependence between $\tan \phi$ and $c$ may be of interest as conventional shear strength parameter characterization involves two random variables $(\tan \phi$ and $c$ ) over a range of $\sigma_{\mathrm{n}}$. Figures $5 \mathrm{a}$ and $5 \mathrm{~b}$ present the correlation analyses for the GCL internal and GCL-GM interface shear strength parameters defined using Sets 3 and 4 respectively. A weak positive trend is noted for the GCL 


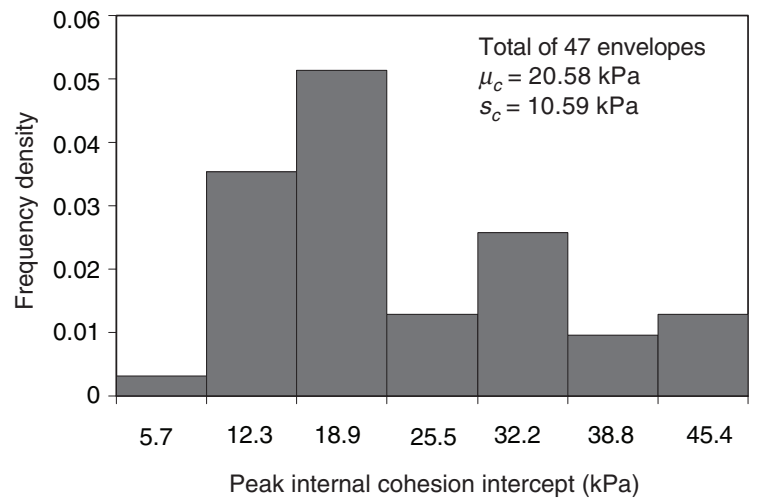

(a)

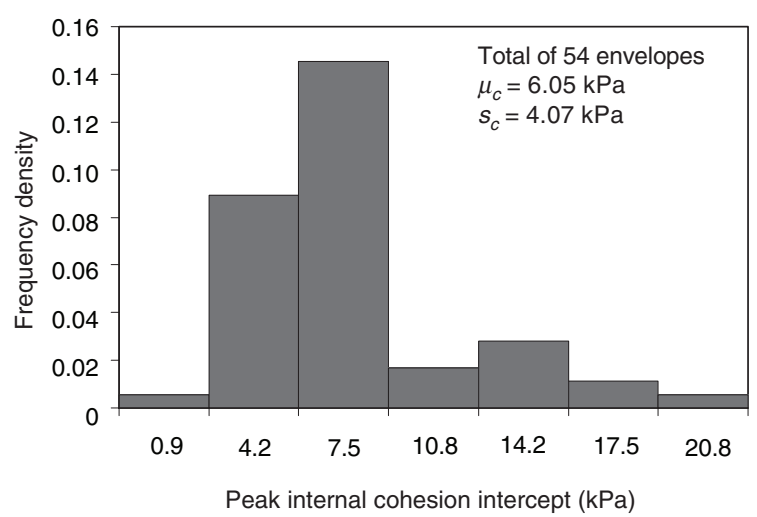

(c)

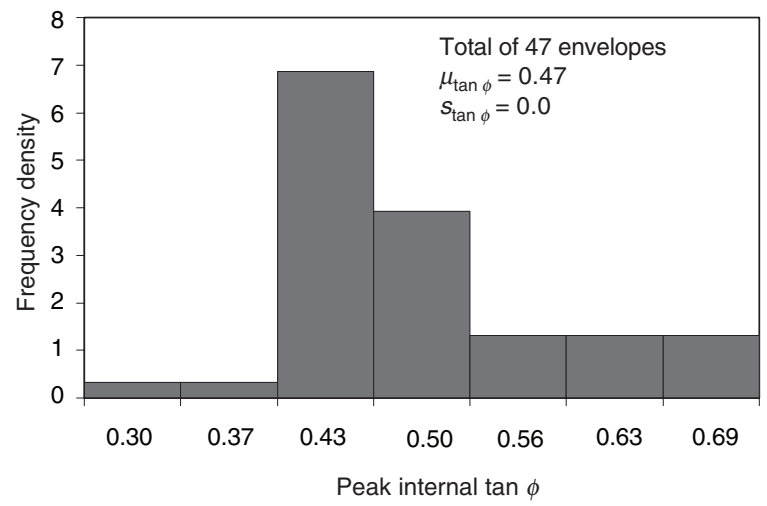

(b)

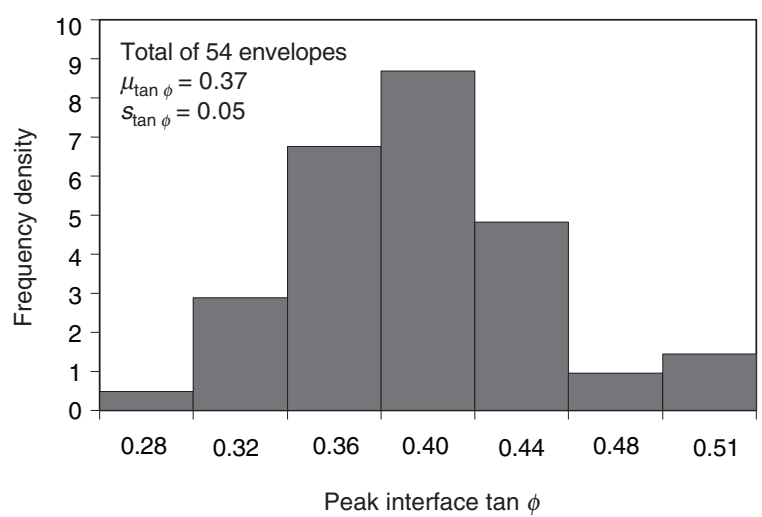

(d)

Figure 4. GCL shear strength parameter probability distributions for Sets 3 and 4 (intra-product, different-lot, same conditioning procedures): (a) cohesion intercept for Set 3; (b) tangent of friction angle for Set 3; (c) cohesion intercept for Set 4; (d) tangent of friction angle for Set 4

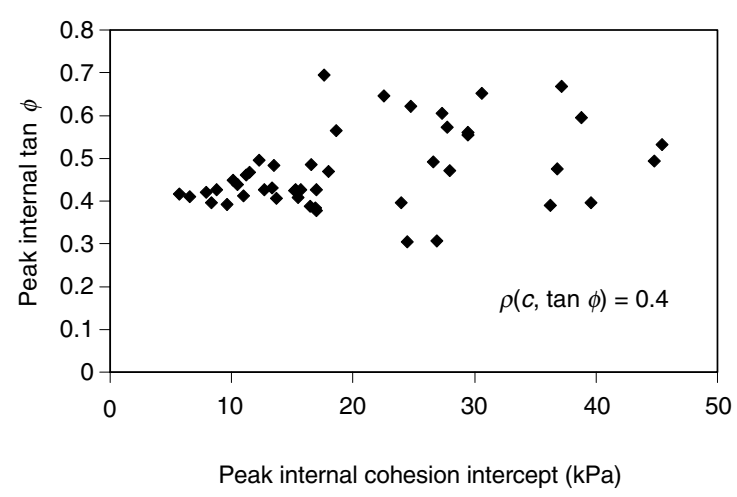

(a)

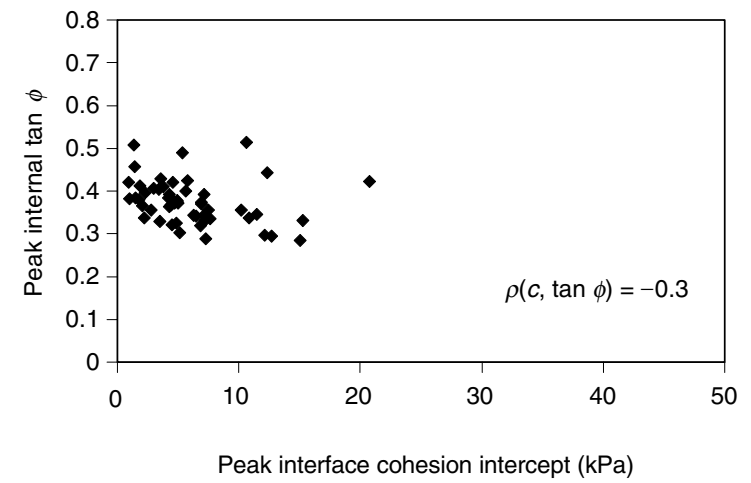

(b)

Figure 5. Correlation between $\tan \phi$ and $c$ for GCL A internal and interface shear strength: (a) Set 3; (b) Set 4

internal shear strength data, and a weak negative trend is noted for the GCL-GM shear strength data.

Table 4 shows the shear strength parameters for the failure envelopes used in Sets 5 and 6. Table 4 also includes information regarding the mean, standard deviation and $\delta$ of the cohesion intercept and friction angle for the failure envelopes in each set. As expected, higher values of $\delta_{c}$ and $\delta_{\tan \phi}$ were obtained for Sets 5 and 6 than those obtained for Sets $1-4$. This is because Sets 1 and 4 are subsets of Sets 5 and 6 , and consequently incorporate more sources of uncertainty. It should be noted that $\delta_{c}$ for Set 6 is nearly 0.8 , which is very high. However, because the cohesion intercept is typically negligible for GCL-GM interface failure envelopes, this variability will not have a significant effect on stability evaluations. Figure 6 shows the GCL A internal peak shear strength (Set 5). The spread in the shear strength data is large, but is constant with $\sigma_{\mathrm{n}}$, at least for the range of $\sigma_{\mathrm{n}}$ in this data set. Figure 7 shows the GCL Atextured HDPE GM interface peak shear strength (Set 6). Unlike the GCL internal shear strength, the spread in the GCL-GM interface shear strength increases with $\sigma_{\mathrm{n}}$. 


\begin{tabular}{|c|c|c|c|}
\hline \multirow{6}{*}{ 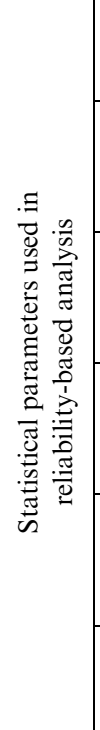 } & 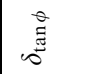 & $\stackrel{t}{0}$ & $\stackrel{\text { İ }}{\text { Oे }}$ \\
\hline & 包 & $\stackrel{0}{0}$ & o. \\
\hline & 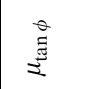 & ò & $\bar{m}$ \\
\hline & $\infty$ & $?$ & $\stackrel{\hat{\imath}}{0}$ \\
\hline & $\sim \frac{\widehat{D}}{2}$ & $\underset{\infty}{+\infty}$ & $\stackrel{2}{2}$ \\
\hline & $\approx$ 飬 & $\stackrel{0}{\dot{\varphi}}$ & $\hat{\alpha}$ \\
\hline \multirow{2}{*}{ 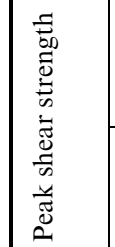 } & $\begin{array}{l}\theta \\
\Xi\end{array}$ & å & 逃 \\
\hline & 。 & & 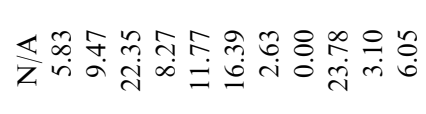 \\
\hline \multicolumn{2}{|l|}{ 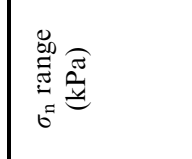 } & 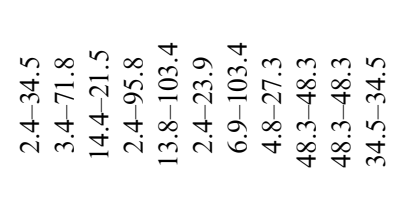 & 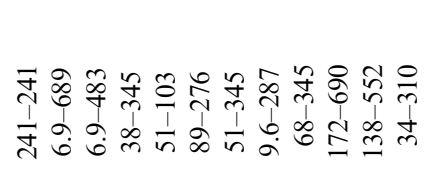 \\
\hline \multirow{4}{*}{ 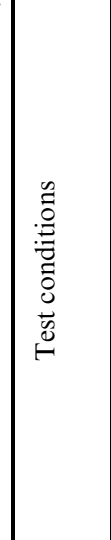 } & 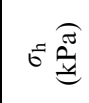 & O E & 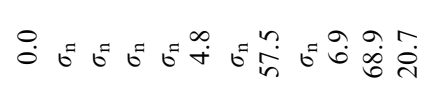 \\
\hline & $\sim \widehat{\Xi}$ & 0000000 H & 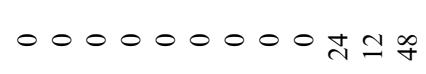 \\
\hline & $\approx \widehat{\Xi}$ & ○ & 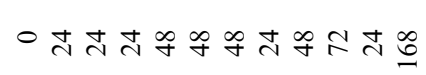 \\
\hline & 党高 & 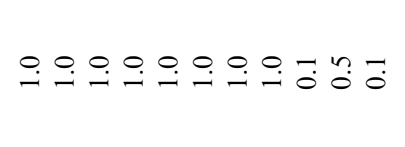 & 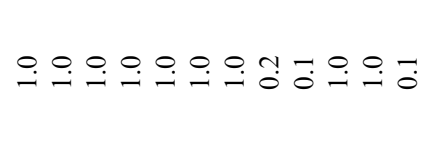 \\
\hline \multicolumn{2}{|c|}{ 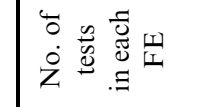 } & $r \bar{\lambda} N \bar{m} m+\forall m-\forall f$ & - \\
\hline \multicolumn{2}{|c|}{ 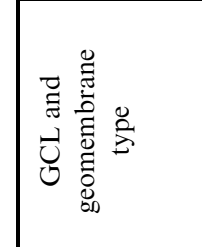 } & $\varangle \ll \ll \ll \ll \ll \ll<\varangle<\varangle$ & 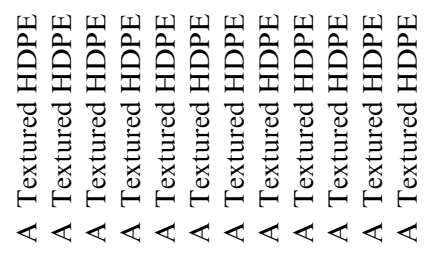 \\
\hline \multicolumn{2}{|c|}{ 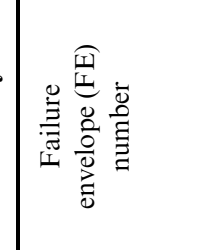 } & 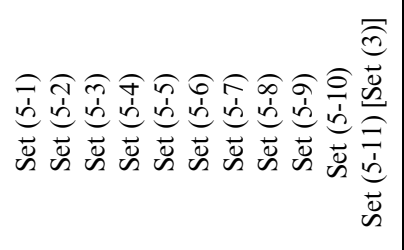 & 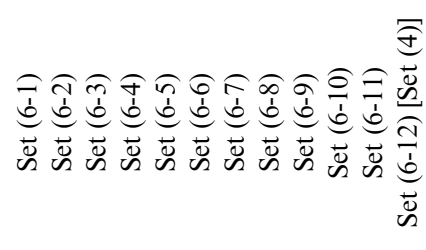 \\
\hline
\end{tabular}

Geosynthetics International, 2004, 11, No. 3 


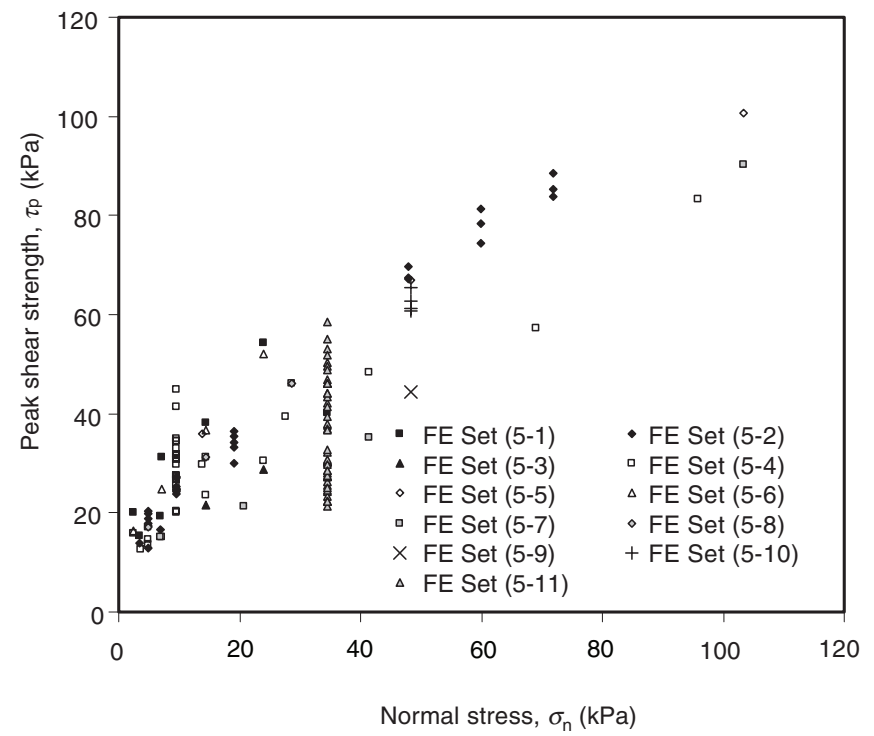

Figure 6. Internal peak shear strength for GCL A tested at normal stresses less than $100 \mathrm{kPa}$ (Set 5: intra-product, different-lot, different conditioning procedures)

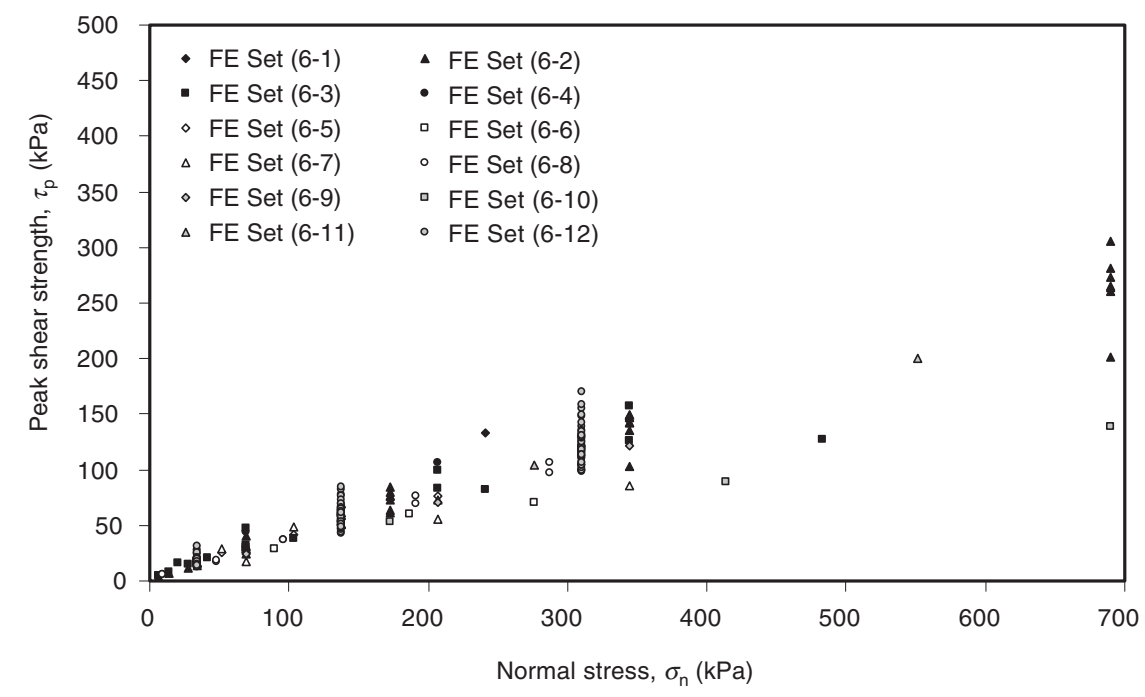

Figure 7. Peak shear strength values for interface between GCL A and a textured HDPE GM tested at normal stresses less than $700 \mathrm{kPa}$ (Set 6: intra-product, different-lot, different conditioning procedures)

3.2.3. Shear strength variability characterization by a global failure envelope approach

Instead of grouping the shear strength values in each set into individual failure envelopes based on similar lots or conditioning procedures, the GCL shear strength variability can also be analysed by performing a global linear regression on the shear strength values in each data set. Subsequently, the outputs of the regression analysis can be used to determine the value of $\delta_{\text {Strength }}^{\mathrm{Lab}}$ at a specified $\sigma_{\mathrm{n}}$ (instead of the coefficient of variation for the shear strength parameters $\delta_{c}$ and $\delta_{\tan \phi}$ ). Shear strength variability corresponding to all eight sets is analysed using this approach. The peak internal shear strength of all GCLs in the database below $\sigma_{\mathrm{n}}=100 \mathrm{kPa}$ (Set 7) is shown in Figure 8 . The spread in the shear strength data is larger than that observed in Set 5 , but it is relatively constant with $\sigma_{\mathrm{n}}$. The peak shear strength of all GCL-GM interfaces in the database (Set 8) is shown in Figure 9.
Similar to Set 6, the spread in the GCL-GM interface shear strength increases with $\sigma_{\mathrm{n}}$.

Table 5 presents the linear regression results for the eight sets in Table 1. For all sets, a weighted leastsquares regression with a linearly increasing standard deviation provided the best fit for the data. One of the outputs of a linear regression model is the standard deviation value (i.e. a measure of how the data are distributed around the best-fit line), which, combined with the parameters of the best-fit line $(c$ and $\tan \phi$ in Table 5), can be used to find a value of $\delta_{\text {Strength }}^{\mathrm{Lab}}$ for any $\sigma_{\mathrm{n}}$ within the $\sigma_{\mathrm{n}}$ bounds of the best-fit line. For the weighted least-squares regression, the standard deviation is a function of $\sigma_{\mathrm{n}}$, whereas for a conventional least-squares regression it is not. In addition to the values of $c$ and $\tan \phi$, Table 5 shows the values of the mean, $\mu$ (the value calculated from the best-fit line), standard deviation, $s$, and $\delta_{\text {Strength }}^{\text {Lab }}$ for $\sigma_{\mathrm{n}}=20 \mathrm{kPa}$ and $\sigma_{\mathrm{n}}=100 \mathrm{kPa}$, which 


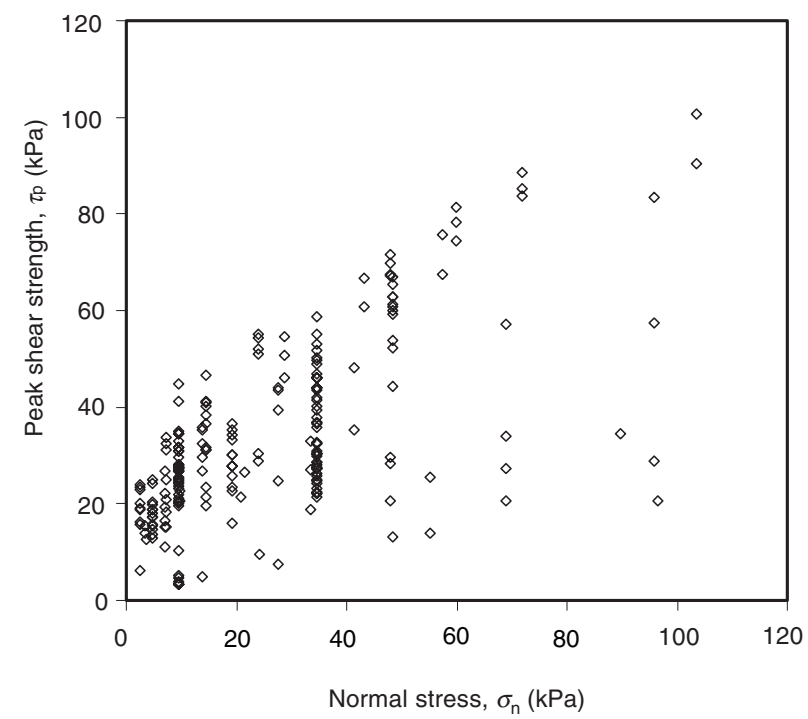

Figure 8. Internal peak shear strength for all GCLs in the database tested under normal stresses less than $100 \mathrm{kPa}$ (Set 7: interproduct, different-lot, different conditioning procedures)

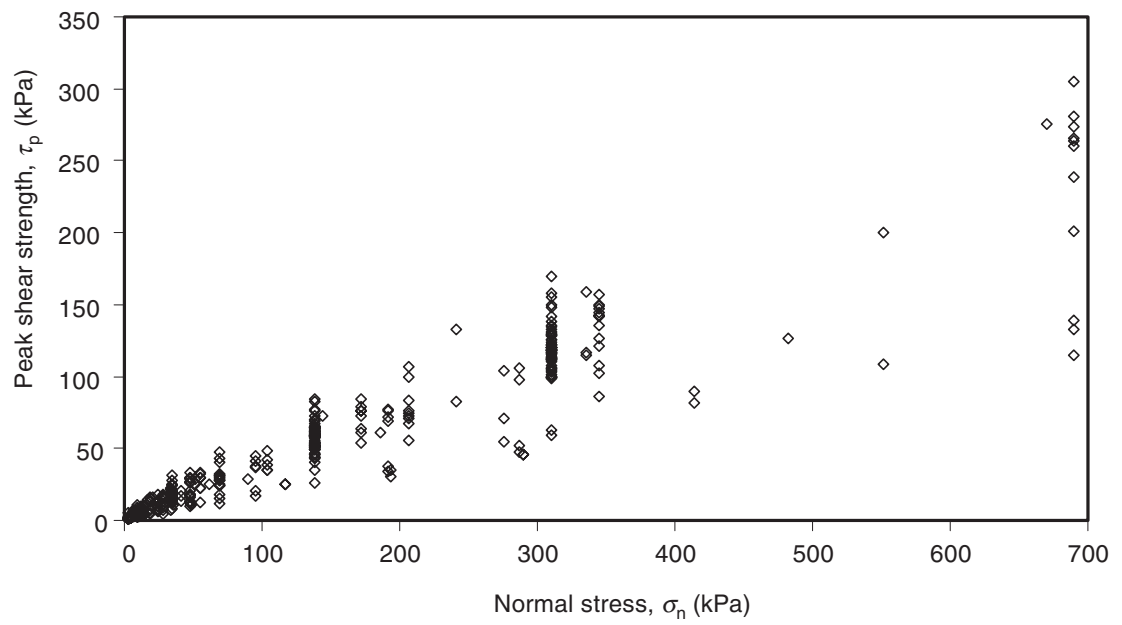

Figure 9. Peak shear strength values for the interface between all GCLs and GMs tested at normal stresses less than $700 \mathrm{kPa}$ (Set 8: inter-product, different-lot, different conditioning procedures)

are representative of landfill cover and liner systems respectively. For the higher $\sigma_{\mathrm{n}}$ of $100 \mathrm{kPa}$, the values of $\delta_{\text {Strength }}^{\mathrm{Lab}}$ are slightly greater for each set of GCL internal shear strength data, but relatively constant for each set of GCL-GM interface shear strength data.

\subsection{Assessment of uncertainty in laboratory GCL shear strength}

3.3.1. Sources of uncertainty in laboratory shear strength variability

In this section, a framework is presented for isolating and interpreting the shear strength variability arising from the different sources of uncertainty discussed in Section 3.1. The eight sets of data listed in Table 1 can be used to isolate these sources. Section 3.2 presented a quantification of the shear strength variability for each set. The laboratory shear strength variability corresponding to each source of uncertainty can be identified so that it may be incorporated into realistic stability analyses. The framework will present equations for the internal shear strength data (Sets 1, 3, 5 and 7) for conciseness, but the same equations can be used for interface shear strength. The variability defined using Set 1 results is expected to be representative of that of GCL internal shear strength when the specific manufacturing lot and the conditioning procedures are clearly established (e.g. if field conditions are well understood, and the conditioning procedures reflect this understanding). Accordingly, the coefficient of variation for same-lot GCL internal laboratory shear strength under constant conditioning procedures, $\delta_{\text {Strength }}^{\mathrm{Lab}, \text { Same-lot }}$, is defined as:

$$
\delta_{\text {Strength }}^{\text {Lab,Same-lot }}=\delta_{\text {Strength }}^{\text {Lab,Set } 1}
$$




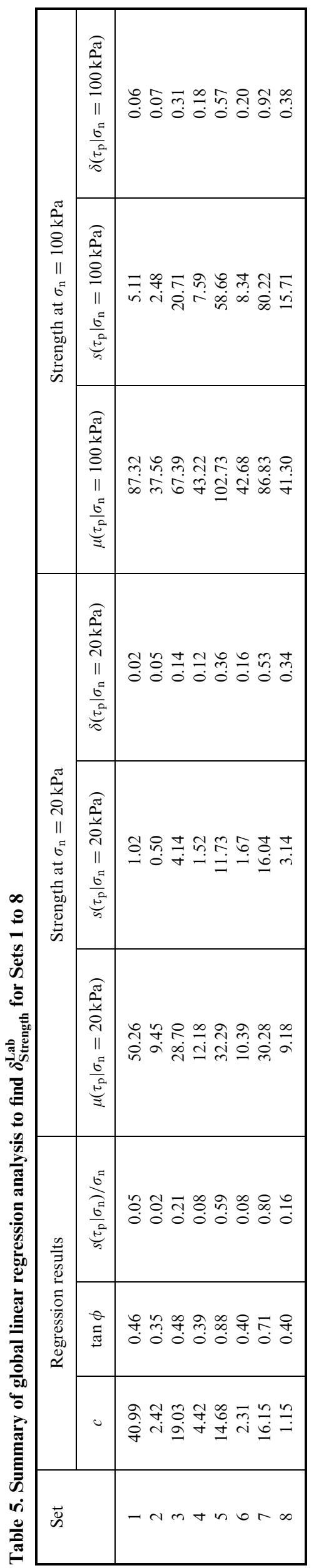

Geosynthetics International, 2004, 11, No. 3 
where $\delta_{\text {Strength }}^{\mathrm{Lab} \text { Set }}$ is the coefficient of variation calculated for Set 1 . The coefficient of variation for same-lot GCLGM interface laboratory shear strength under constant conditioning procedures can be defined in a similar manner using the variability of Set 2 results. The variability defined using Set 3 results is expected to be representative of that of GCL internal shear strength when the conditioning procedures are clearly established but the manufacturing lot is not, or when a project requires GCLs from several manufacturing lots for a single slope. Accordingly, the coefficient of variation for different-lot GCL internal laboratory shear strength under constant conditioning procedures, $\delta_{\text {Strength }}^{\text {Lab, Different-lot }}$ is defined as

$$
\delta_{\text {Strength }}^{\text {Lab,Different-lot }}=\sqrt{\left(\delta_{\text {Strength }}^{\text {Lab,Set 3 }}\right)^{2}-\left(\delta_{\text {Strength }}^{\text {Lab,Set 1 }}\right)^{2}}
$$

where $\delta_{\text {Strength }}^{\mathrm{Lab} 3}$ is the coefficient of variation calculated for Set 3. The coefficient of variation for different-lot GCL-GM interface laboratory shear strength under constant conditioning procedures can be defined in a similar manner using the variability of Set 4 results. The variability defined using Set 5 results is expected to be representative of the overall GCL A internal shear strength when the conditioning procedures are not defined (e.g. if field conditions are not understood, or conditioning procedures do not reflect field conditions). Accordingly, the coefficient of variation for different-lot GCL internal laboratory shear strength under varying conditioning procedures, $\delta_{\text {Strength }}^{\mathrm{Lab} \text {, Conditions }}$, is defined as

$$
\begin{aligned}
& \delta_{\text {Strength }}^{\text {Lab,Conditions }} \\
& =\sqrt{\left(\delta_{\text {Strength }}^{\text {Lab,Set 5 }}\right)^{2}-\left(\delta_{\text {Strength }}^{\text {Lab,Set 3 }}\right)^{2}-\left(\delta_{\text {Strength }}^{\text {Lab,Set 1 }}\right)^{2}}
\end{aligned}
$$

where $\delta_{\text {Strength }}^{\text {Lab, Set } 5}$ is the coefficient of variation calculated for Set 5. The coefficient of variation for different-lot GCL-GM interface laboratory shear strength under varying conditioning procedures can be defined in a similar manner using the variability of Set 6 results. The variability defined using Set 7 results is expected to be representative of the internal shear strength of all GCLs, reinforced and unreinforced, when the conditioning procedures are not defined. Accordingly, the coefficient of variation for intra-product GCL internal laboratory shear strength, $\delta_{\text {Strength }}^{\text {Lab,Intra-product }}$, is defined as

$$
\begin{aligned}
& \delta_{\text {Strength }}^{\text {Lab,Intra-product }} \\
& =\sqrt{\left(\delta_{\text {Strength }}^{\text {Lab,Set 7 }}\right)^{2}-\left(\delta_{\text {Strength }}^{\text {Lab,Set 5 }}\right)^{2}-\left(\delta_{\text {Strength }}^{\text {Lab,Set 3 }}\right)^{2}-\left(\delta_{\text {Strength }}^{\text {Lab,Set 1 }}\right)^{2}}
\end{aligned}
$$

where $\delta_{\text {Strength }}^{\mathrm{Lab} \text {,Se } 7}$ is the coefficient of variation calculated for Set 7. The coefficient of variation for intra-product GCL-GM interface laboratory shear strength can be defined in a similar manner using the variability defined using Set 8 results.

Table 6 provides a summary of the coefficients of variation in GCL internal and GCL-GM interface laboratory shear strength calculated from the values of $\delta_{c}$ and $\delta_{\tan \phi}$ obtained using the individual failure envelope analyses for Sets 1-6 in Tables 2, 3 and 4. For GCL internal shear strength, an increase in the uncertainty in $c$ and $\tan \phi$ is observed when moving from same-lot specimens to different-lot specimens. Conditioning procedures led to significant uncertainty in $\tan \phi$ but negligible uncertainty in $c$. For GCL-GM interface shear strength, an increase in the uncertainty in $c$ and $\tan \phi$ is observed when moving from same-lot specimens to different-lot specimens. Conditioning procedures also led to a significant increase in uncertainty for both $c$ and $\tan \phi$. Table 6 also provides a summary of the coefficients of variation in GCL internal and GCLGM interface laboratory shear strength calculated from the values of $\delta_{\text {Strength }}^{\mathrm{Lab}}$ corresponding to $\sigma_{\mathrm{n}}=20 \mathrm{kPa}$ and $\sigma_{\mathrm{n}}=100 \mathrm{kPa}$. They were obtained using the linear regression approach for Sets 1-8 (Table 5). For GCL internal shear strength, an increase in $\delta_{\text {Strength }}^{\mathrm{Lab}}$ is observed when moving from same-lot specimens to different-lot specimens. Conditioning procedures led to significant uncertainty in $\delta_{\text {Strength }}^{\mathrm{Lab}}$ for GCL internal shear strength. For GCL-GM interface shear strength, an increase in $\delta_{\text {Strength }}^{\mathrm{Lab}}$ is observed when moving from same-lot specimens to different-lot specimens. Conditioning procedures led to slight uncertainty in $\delta_{\text {Strength }}^{\text {Lab }}$ for GCL-

\begin{tabular}{|c|c|c|c|c|c|}
\hline \multirow[t]{2}{*}{$\begin{array}{l}\text { Material } \\
\text { description }\end{array}$} & \multirow[t]{2}{*}{ Source of uncertainty } & \multicolumn{2}{|c|}{$\begin{array}{l}\text { FE approach to } \\
\delta_{\text {Strength }}^{\mathrm{Lab}}\end{array}$} & \multicolumn{2}{|c|}{ Linear regression approach } \\
\hline & & $\delta_{c}$ & $\delta_{\tan \phi}$ & $\begin{array}{c}\delta_{\text {Strength }}^{\mathrm{Lab}} \\
\text { at } \sigma_{\mathrm{n}}=20 \mathrm{kPa}\end{array}$ & $\begin{array}{c}\delta_{\text {Strength }}^{\text {Lab }} \\
\text { at } \sigma_{\mathrm{n}}=100 \mathrm{kPa}\end{array}$ \\
\hline GCL internal & $\begin{array}{c}\text { Intra-product repeatability (same-lot) } \\
\text { Intra-product material variability (different-lot) } \\
\text { Conditioning variability } \\
\text { Inter-product material variability }\end{array}$ & $\begin{array}{l}0.10 \\
0.50 \\
0.02 \\
\mathrm{~N} / \mathrm{A}\end{array}$ & $\begin{array}{l}0.03 \\
0.19 \\
0.36 \\
\mathrm{~N} / \mathrm{A}\end{array}$ & $\begin{array}{l}0.02 \\
0.14 \\
0.33 \\
0.36\end{array}$ & $\begin{array}{l}0.06 \\
0.30 \\
0.48 \\
0.66\end{array}$ \\
\hline $\begin{array}{l}\text { GCL-GM } \\
\text { interface }\end{array}$ & $\begin{array}{c}\text { Intra-product repeatability (same-lot) } \\
\text { Intra-product material variability (different-lot) } \\
\text { Conditioning variability } \\
\text { Inter-product material variability }\end{array}$ & $\begin{array}{l}0.35 \\
0.57 \\
0.23 \\
\mathrm{~N} / \mathrm{A}\end{array}$ & $\begin{array}{l}0.03 \\
0.13 \\
0.19 \\
\mathrm{~N} / \mathrm{A}\end{array}$ & $\begin{array}{l}0.05 \\
0.11 \\
0.09 \\
0.27\end{array}$ & $\begin{array}{l}0.07 \\
0.16 \\
0.06 \\
0.27\end{array}$ \\
\hline
\end{tabular}
GM interface shear strength. In summary, the results of the two approaches used to define uncertainty are consistent, and indicate that the GCL and GM speci-

Table 6. Summary of $\delta_{\text {Strength }}^{\mathrm{Lab}}$ values for different sources of uncertainty 
mens from different manufacturing tend to have greater shear strength variability than those from similar lots, different GCL and GM products lead to significant variability in shear strength, and conditioning procedures have a greater effect on GCL internal shear strength than on GCL-GM interface shear strength.

\subsubsection{Framework for assessment of uncertainty in laboratory shear strength}

As laboratory GCL shear strength testing is not only expensive but also time consuming, a rational plan must be established to assess the value of $\delta_{\text {Strength }}^{\mathrm{Lab}}$ that will be used in a project. This section presents a framework for incorporating the laboratory shear strength variability arising from different sources of uncertainty calculated in the previous section into the value of $\delta_{\text {Strength }}^{\mathrm{Lab}}$. First, the different motivations for a testing program should be investigated. Stability analyses of landfill covers or base liners including GCL products should ideally be conducted after characterizing the shear strength of relevant interfaces from a project-specific testing program in which the field conditions are understood and reflected in the conditioning procedures in the laboratory (e.g. Sets 1 and 4). This may involve shear strength testing of the relevant interfaces using GCL specimens from the manufacturing lots to be used during construction. Such an approach implies that the GCL material must be sole-sourced in design specifications, which is often not cost-effective owing to a lack of flexibility during the bidding process. Because of cost and time considerations, of the interest in flexibility regarding product selection, and of the availability of increasingly large shear strength databases, designers have often avoided project-specific testing programs. Instead, the use of product-specific shear strength results (e.g. Sets 5 and 6) or intra-product results (e.g. Sets 7 and 8) compiled in databases such as the GCLSS database have been appealing alternatives when the field conditions are not identified, or the product to be used in the project is not selected.

In addition to selecting a project-specific or productspecific data set, the uncertainty in the laboratory shear strength data best representing the conditions in the field depends on the size of the project. If the project is small enough so that the cover or liner slope may be constructed using a single GCL manufacturing lot, the inter-product repeatability will characterize the shear strength variability. On the other hand, if the project requires several GCL manufacturing lots to construct the slope, the inter-product material variability will characterize the variability. Testing experience at SGI laboratory suggests that, when multiple rolls are required for a project, the rolls are typically supplied from different manufacturing lots. In addition, manufacturers typically use different sources of sodium bentonite and carrier geosynthetics over time. Consequently, a slope requiring several rolls may have uncertainty in shear strength arising from the intraproduct material variability. Depending on the size of the project, a testing program must include enough tests to encompass the variability expected within a manufacturing lot $\left(\delta_{\text {Strength }}^{\text {Lab,Sat }}\right)$ as well as within different manufacturing lots ( $\left.\delta_{\text {Strength }}^{\text {Lab, Different-lot }}\right)$.

If no project-specific testing is conducted for GCL shear strength, the uncertainty may be quantified from the coefficients of variation discussed in Section 3.3.1. In other words, if no project-specific tests are conducted, the uncertainty is represented by the variability for tests on a representative range of possible products without knowledge of the specific field conditions and how those conditions would affect the laboratory shear strength. As a worst-case scenario, the uncertainty associated with no tests, $\delta_{\text {Strength }}^{\text {Lab,No tests }}$, is defined as

$$
\begin{aligned}
& \delta_{\text {Strength }}^{\text {Lab, No tests }} \\
& =\sqrt{\left(\delta_{\text {Strength }}^{\text {Lab,Inter-product }}\right)^{2}+\left(\delta_{\text {Strength }}^{\text {Lab, Conditioning }}\right)^{2}\left(\delta_{\text {Strength }}^{\text {Lab, Different-lot }}\right)^{2}+\left(\delta_{\text {Strength }}^{\text {Lab,lat }}\right)^{2}}
\end{aligned}
$$

In this situation, the constituent sources of uncertainty in $\delta_{\text {Strength }}^{\text {Lab, No test }}$ can be obtained from a database such as the one presented in this study. Project-specific testing will logically lead to a reduction in the expected laboratory shear strength variability.

The contribution to the shear strength variability related to inter-product variations can be eliminated by selecting a specific GCL product to be used in the project. This implies that the GCL material must be solesourced in the design specifications and that changes in the product between design and construction are not allowed. Uncertainty related to conditioning may be reduced by conducting tests using conditioning procedures representative of those in the field. In the following discussions, it is assumed that the projectspecific tests conducted adequately reflect the field conditions.

\subsection{Uncertainty in using laboratory strength to represent mobilized strength}

An additional contribution to the coefficient of variation in the available shear strength arises from differences between the strength mobilized in the field and that measured in a laboratory test. This source of uncertainty, which has been commonly attributed to uncertainty in the slope stability model, is represented by the coefficient of variation $\Omega_{\text {Strength }}^{\mathrm{Model}}$. The laboratory tests are assumed to provide an unbiased estimate of the strength available in the field. That is, the conditioning procedures such as hydration time, consolidation time, shear displacement rate, and applied normal stress during hydration, consolidation and shearing, are deemed representative of the expected conditions in the field. However, even if test results are unbiased, there is still added uncertainty when laboratory results are used in interpreting field behavior.

The value for $\Omega_{\text {Strength }}^{\text {Model }}$ can be established based on laboratory testing programs that were conducted coincidentally with failure back-analyses. For example, Bjerrum (1973) and Terzaghi et al. (1996) compared the undrained shear strength in the field based on a backanalysis of failures in natural clay slopes with those 
measured using field vane tests. After accounting for biases related to the plasticity of the soil, the scatter in the back-analysed (field-mobilized) versus laboratory measured strength was quantified by a coefficient of variation of approximately 0.21 . Also in natural clay slopes, Skempton (1985) compared the drained, residual shear strength obtained from back-analysis of reactivated slope failures with the strength measured in laboratory tests. The scatter in the relationship between mobilized and measured strength corresponded to a coefficient of variation of approximately 0.15 . In landfill liners, Gilbert et al. (1998) used a coefficient of variation of approximately 0.13 to reflect model uncertainty in the slope failure for the Kettleman Hills landfill, which occurred along a smooth GM-compacted clay liner interface. Additional uncertainty was associated with the mobilization of large-displacements, which led to the need to use the residual strength obtained from laboratory tests. Finally, in a landfill cover failure that took place between a reinforced GCL and a smooth geomembrane, the strength mobilized in the field was within $25 \%$ of that estimated from laboratory shear tests (Liu et al. 1997). In this case, the normal stress was extremely small (a few $\mathrm{kPa}$ ), and most of the model uncertainty was related to the magnitude of porewater and gas pressures present at the time of failure. In summary, based on reported field cases, $\Omega_{\text {Strength }}^{\text {Mod }}$ is expected to range from 0.1 and 0.2 for a typical case.

\section{EFFECT OF UNCERTAINTY IN SHEAR STRENGTH ON THE RELATIONSHIP BETWEEN PROBABILITY OF FAILURE AND SAFETY FACTOR}

\subsection{Motivation and assumptions}

Geotechnical systems designed with safety factor (FS) values typically used in practice may correspond to different safety levels: that is, different values of the probability of failure $p_{\mathrm{f}}$. However, the project-specific and product-specific GCL internal and interface shear strength results can be used in this study to correlate the $p_{\mathrm{f}}$ with the FS defined using conventional limit equilibrium analyses. Accordingly, the analyses presented in this section aim at obtaining the $p_{\mathrm{f}}$ that corresponds to the different levels of uncertainty discussed in Section 3 using reliability-based analyses. First, a correlation will be established between reliability-based and conventional stability analyses. Specifically, the $p_{\mathrm{f}}$ calculated using a first-order, second moment reliability method will be correlated with the FS defined using conventional veneer limit equilibrium analyses. Second, the $p_{\mathrm{f}}$ calculated using a general reliability-based approach will be used to quantify the effect of uncertainty in GCL shear strength on the $p_{\mathrm{f}}$. This is useful to assess the benefit of conducting project-specific laboratory testing.

\subsection{First-order, second moment analysis of a veneer slope}

In this section, a first-order, second moment (FOSM) reliability analysis is used to define the value of $p_{\mathrm{f}}$ for a veneer slope over a range of slope inclination values. In addition, conventional limit equilibrium analyses are conducted to define the veneer FS. The reliability-based approach has been employed by Christian et al. (1994) and Duncan (2000) for different geotechnical applications to relate the variability in shear strength parameters with the $p_{\mathrm{f}}$. This approach has also been used recently for landfill design applications (Koerner and Koerner 2001; Sabatini et al. 2002). The first-order, second moment reliability approach was selected as it allows the incorporation of uncertainty into the conventional expression for FS, such as that used in veneer stability analyses. A simple veneer stability analysis is useful to illustrate the relationship between $p_{\mathrm{f}}$ and FS. Figure 1 illustrates a typical GCL-lined veneer with a conventional safety factor given by Equation 2. It is recognised that the results of stability analyses often involve more complex geometry of the liner system (e.g. in two-dimensional problems). However, for given project-specific and product-specific shear strength properties, veneer stability analyses are expected to provide good insight into relationships between $p_{\mathrm{f}}$ and FS. The statistical information for the shear strength parameters characterized by the individual failure envelope approach in Section 3.2 .2 (i.e. $\delta_{c}$ and $\delta_{\tan \phi}$ ) for the first six sets of intra-product GCL internal and interface shear strength data are incorporated into the reliability-based veneer stability analysis.

The Appendix presents the first-order, second moment reliability methodology used to calculate the uncertainty in FS. The reliability methodology provides an exact solution for the mean and the variance of FS (but not the probability distribution) for a linear function of nonnormal variables. The following assumptions are made for the stability analyses conducted in this study:

- The relevant failure plane along which failure occurs involves the GCL component (i.e. the failure occurs internally through the GCL or along the GCL-GM interface, depending on the set under investigation).

- The thickness of the GCL is negligible when compared with the thickness of the soil veneer. Accordingly, the different interfaces analysed in the veneer system have similar loading conditions.

- The correlation between $c$ and $\tan \phi$ is considered. As the data from Sets 3 and 4 are significant in number and the conditioning procedures used are representative of field conditions, it is assumed that the correlation between $c$ and $\tan \phi$ obtained for these sets is representative of GCL internal and GCL-GM interface shear strength. So, the correlation coefficient between $c$ and $\tan \phi$ from Set 3 (Table 3 ) is used for Sets 1 and 5, and the correlation coefficient between $c$ and $\tan \phi$ from Set 4 (Table 3) is used for Sets 2 and 6.

- The veneer soil and geometry variables are also characterized as random variables. As the veneer soil 
and geometry are the same for each of the first six sets, defining them as random variables does not affect the comparison. However, using random veneer soil and geometry values provides a realistic representation of variability in the field. Specifically, a soil unit weight $\gamma$ with a mean of $20 \mathrm{kN} / \mathrm{m}^{3}$ and a standard deviation of $1.5 \mathrm{kN} / \mathrm{m}^{3}$, a veneer thickness $T$ with a mean of $1 \mathrm{~m}$ and a standard deviation of $0.1 \mathrm{~m}$, and a slope inclination $\psi$ with a mean of $20^{\circ}$ and a standard deviation of $1^{\circ}$ were adopted. The mean values adopted in this example slope correspond to a $\sigma_{\mathrm{n}}$ of roughly $20 \mathrm{kPa}$ being applied to the GCL.

- The uncertainty associated with using laboratory strength to represent the field mobilized shear strength $\Omega_{\text {Strength }}^{\text {Model }}$ is assumed to be 0.1 based on the discussion in Section 3.4.

- Failure along the relevant failure plane is assumed to be governed by the peak shear strength. Accordingly, only peak shear strength values are used in the analyses presented herein. The important decision on whether failure along a GCL-lined system is governed by peak or residual (large-displacement) shear strength parameters is beyond the scope of this paper, as this very important topic has been addressed in recent studies (e.g. Gilbert 2001; Thiel 2001). Consequently, use of this assumption should not be construed as an endorsement by the authors of the use of peak shear strength parameters in the design of systems involving GCLs. Nonetheless, quantification of the $p_{\mathrm{f}}$ (in addition to the FS) can provide additional decision-making information regarding the appropriate shear strength parameters to adopt in design.

Because the mean values $\mu_{\mathrm{c}}$ and $\mu_{\tan \phi}$ for Sets $1-6$ are different, comparison between the results of a first-order, second moment reliability analysis incorporating the means and standard deviations of these data sets would be difficult to interpret. For this reason, the values of $c$ and $\tan \phi$ defined for a single example GCL internal envelope and a single example GCL-GM envelope from the GCLSS database (each with three shear strength data points) are used as the mean values in the following first-order, second moment reliability-based veneer stability analysis. Figure 10 shows the GCL A internal

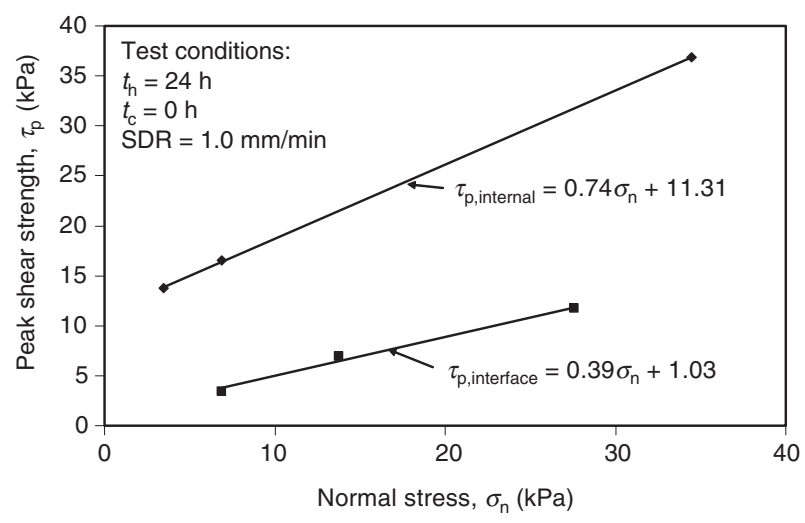

Figure 10. Example internal GCL A and GCL A-GM interface failure envelopes (without variability) for FOSM infinite slope analysis

and interface failure envelopes. The GCL internal and GCL-GM interface specimens have similar conditioning procedures. The mean values of $c$ and $\tan \phi$ for the example GCL A internal failure envelope are used in association with different standard deviation values of $c$ and $\tan \phi$ defined using the $\delta_{c}$ and $\delta_{\tan \phi}$ values reported in Tables 2, 3 and 4 for Sets 1, 3, and 5, respectively. Similarly, the mean values of $c$ and $\tan \phi$ for the GCL AGM interface are used in association with different standard deviation values of $c$ and $\tan \phi$ defined using the $\delta_{c}$ and $\delta_{\tan \phi}$ values reported in Tables 2, 3 and 4 for Sets 2,4 , and 6 , respectively. This procedure exemplifies how the variability data presented in this paper may be used in a practical situation, and allows a straightforward assessment of the effect of the increasing variability associated with the different sets.

Table 7 shows the results of the first-order, second moment reliability analysis for veneer stability obtained using the variability data from Sets $1-6$. The conventional FS was calculated using the $c$ and $\tan \phi$ values from the example failure envelopes in Figure 10. For the GCL internal failure envelope the calculated FS is 3.69, which is higher than that typically adopted in engineering design. For the GCL-GM interface failure envelope the calculated FS is 1.23 , which is within the range of typical FS values adopted in design. From a

Table 7. Results of the first-order, second moment example with and without correlation

\begin{tabular}{|c|c|c|c|c|c|c|c|c|}
\hline \multirow{2}{*}{$\begin{array}{c}\text { Set } \\
\text { number }\end{array}$} & \multirow[t]{2}{*}{ Set description } & \multirow{2}{*}{$\mu_{\mathrm{FS}}$} & \multicolumn{3}{|c|}{ FOSM method with correlation } & \multicolumn{3}{|c|}{ FOSM method without correlation } \\
\hline & & & $s_{\mathrm{FS}}$ & $\beta$ & $p_{\mathrm{f}}$ & $s_{\mathrm{FS}}$ & $\beta$ & $p_{\mathrm{f}}$ \\
\hline 1 & GCL A internal & 3.69 & 0.31 & 15.45 & 0 & 0.30 & 16.10 & 0 \\
\hline 2 & GCL A - textured HDPE GM interface & 1.23 & 0.09 & 2.97 & $1.49 \times 10^{-3}$ & 0.09 & 2.80 & $2.55 \times 10^{-3}$ \\
\hline 3 & GCL A internal & 3.69 & 1.10 & 4.32 & $7.70 \times 10^{-6}$ & 0.97 & 4.92 & $4.33 \times 10^{-7}$ \\
\hline 4 & GCL A - textured HDPE GM interface & 1.23 & 0.17 & 1.48 & $6.94 \times 10^{-2}$ & 0.19 & 1.27 & $1.02 \times 10^{-1}$ \\
\hline 5 & GCL A internal & 3.69 & 1.44 & 3.28 & $5.25 \times 10^{-4}$ & 1.23 & 3.88 & $5.29 \times 10^{-5}$ \\
\hline 6 & GCL A - texured HDPE GM interface & 1.23 & 0.26 & 0.90 & $1.83 \times 10^{-1}$ & 0.29 & 0.78 & $2.19 \times 10^{-1}$ \\
\hline
\end{tabular}

Note: $\mu_{\psi}=20^{\circ}, \mathrm{s}_{\psi}=1^{\circ}$

$\mu_{T}=1 \mathrm{~m}, s_{T}=0.05 \mathrm{~m}$

$\mu_{\gamma}=20 \mathrm{kN} / \mathrm{m}^{3}, s_{\gamma}=1.5 \mathrm{kN} / \mathrm{m}^{3}$

Internal example envelope: $\mu_{\tan \phi}=0.74, \mu_{c}=11.31 \mathrm{kPa}$

Interface example envelope: $\mu_{\tan \phi}=0.39, \mu_{c}=1.03 \mathrm{kPa}$ 


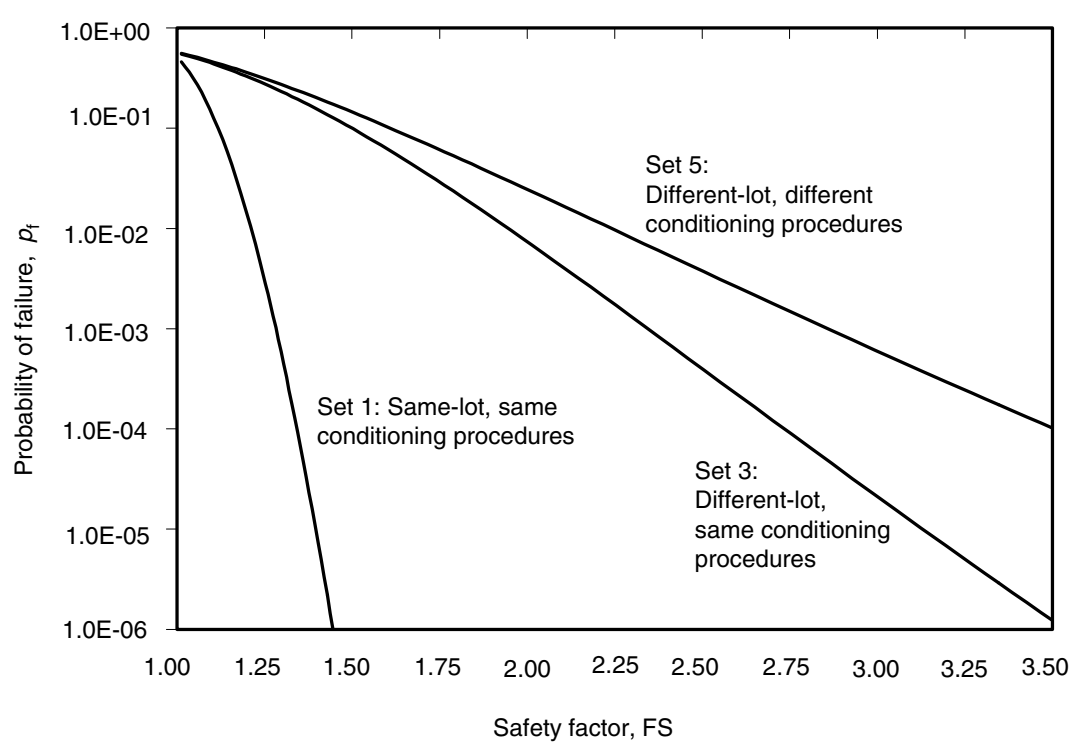

Figure 11. FOSM analysis for infinite slope stability conducted using GCL internal shear strength (Sets 1, 3 and 5). Note: $\gamma=20 \mathrm{~kg} / \mathrm{m}^{3}, T=1 \mathrm{~m}$

deterministic point of view, the slope is stable with respect to both GCL internal and GCL-GM interface shear strength.

Table 7 includes the standard deviation of the FS, the reliability index and the $p_{\mathrm{f}}$ for two cases: accounting for the correlation between $c$ and $\tan \phi$ and not accounting for this correlation. For GCL internal shear strength without correlation, the $p_{\mathrm{f}}$ increases from approximately 0.0 for the repeatability data (Set 1) to approximately $8 \times 10^{-6}$ for the different-lot data with similar conditioning procedures (Set 3 ). The $p_{\mathrm{f}}$ is as high as $5 \times 10^{-4}$ for the different-lot data with different conditioning procedures (Set 5). Increasing the variability in GCL internal shear strength leads to a marked increase in $p_{\mathrm{f}}$ for the veneer system. Accounting for the positive correlation between $c$ and $\tan \phi$ (Table 3) led to a similar trend with lower $p_{\mathrm{f}}$. For GCL-GM interface shear strength without correlation, the $p_{\mathrm{f}}$ increases from $1.5 \times 10^{-3}$ for the repeatability data (Set 2) to $6.9 \times 10^{-2}$ for the different-lot data with similar conditioning procedures (Set 4). The $p_{\mathrm{f}}$ is as high as 0.18 for the different-lot data with different conditioning procedures (Set 6). Also, in this case, increasing the variability in GCL-GM interface shear strength leads to an increase in $p_{\mathrm{f}}$ for the veneer system. The results in this example lead to an unacceptable $p_{\mathrm{f}}$ for the given slope conditions. Accounting for the negative correlation between $c$ and $\tan \phi$ observed for GCL-GM interface shear strength (see Table 3) leads to the same trend with higher $p_{\mathrm{f}}$.

Figure 11 shows the relationship between $p_{\mathrm{f}}$ and FS obtained using the GCL internal shear strength parameters shown in Figure 10 with the $\delta_{c}$ and $\delta_{\tan \phi}$ values that correspond to Sets 1, 3 and 5. For example, a $p_{\mathrm{f}}$ of $10^{-2}$ corresponds to an FS of approximately 1.20 for Set 1, 1.5 for Set 3 and 1.75 for Set 5. For this level of safety, the results obtained for the same-lot and different-lot specimens tested under constant test conditions corre- spond to an FS of 1.5, which is typically used as a design criterion for landfill slopes. The additional uncertainty in shear strength present in Set 5 because the test conditions are variable requires a higher FS to reach the same level of safety. Figure 12 was developed similarly to Figure 11 and shows the relationship between $p_{\mathrm{f}}$ and FS obtained using the GCL-GM interface shear strength parameters shown in Figure 10 with the $\delta_{c}$ and $\delta_{\tan \phi}$ values that correspond to Sets 2, 4 and 6. Figure 12 illustrates that a $p_{\mathrm{f}}$ of $10^{-2}$ corresponds to an FS of 1.23 for Set 2, 1.85 for Set 4 , and 2.25 for Set 6 . While the effect of uncertainty related to conditioning procedures is not as significant as in the case of internal shear strength (Figure 11), the FS values associated with a $p_{\mathrm{f}}$ of $10^{-2}$ can be significantly greater than the typical value of 1.5 conventionally adopted in design when different-lot specimens are used.

\subsection{General reliability-based analysis to quantify the effect of uncertainty}

The safety factor FS that is needed to reach the same level of safety (i.e. the same probability of failure $p_{\mathrm{f}}$ ) when considering increasing levels of shear strength variability (e.g. from the variability of Set 1 to that of Set 3 to that of Set 5, or from the variability of Set 2 to that of Set 4 to that of Set 6 ) is investigated in this section. To quantify the effect of the level of variability, the analyses presented in this section assume that the variability in laboratory shear strength equals that in the field (i.e. $\Omega_{\text {Strength }}^{\text {Mol }}$ is neglected). Specifically, the effect of changing levels of variability on the FS required for design is evaluated using the values of $\delta_{\text {Strength }}^{\mathrm{Lab}}$ of the shear strength corresponding to a $\sigma_{\mathrm{n}}=20 \mathrm{kPa}$, obtained from the linear regression analysis (Table 6). A value of 0.1 is used for $\delta_{\text {Stress }}$ to reflect a typical static landfill stability analysis, and no correlation is used in this analysis. The reliability index is obtained using Equation 8 , and the $p_{\mathrm{f}}$ is calculated using Equation 4. 


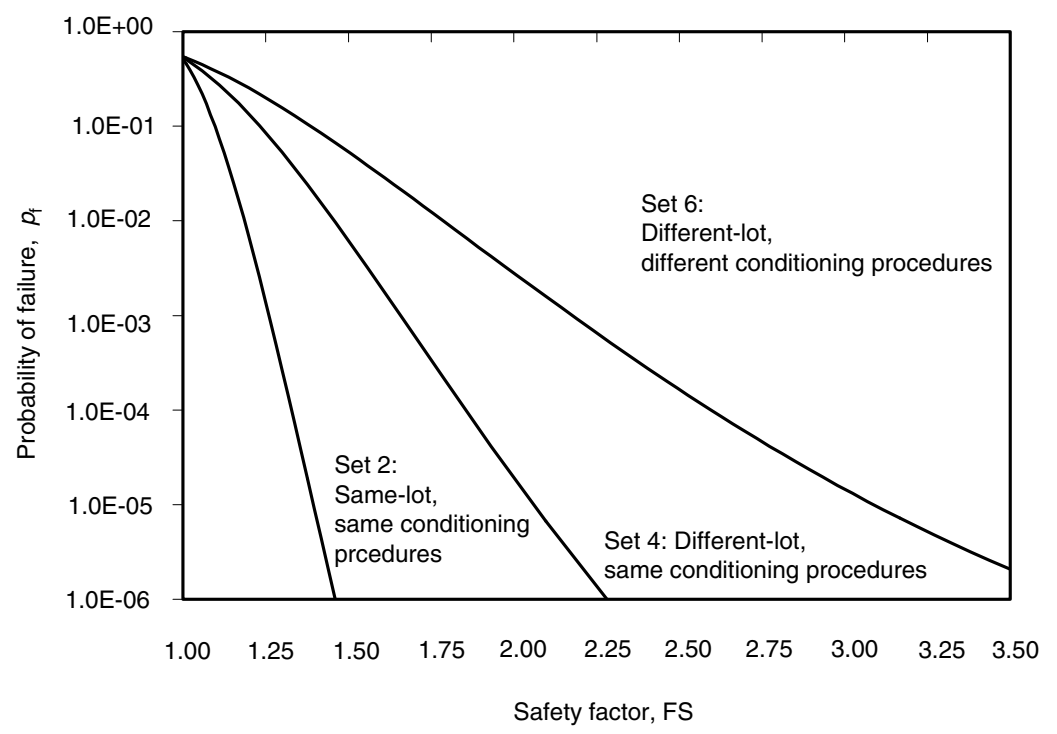

Figure 12. FOSM analysis for infinite slope stability conducted with GCL-GM interface shear strength (Sets 2, 4 and 6). Note: $\gamma=20 \mathrm{~kg} / \mathrm{m}^{3}, T=1 \mathrm{~m}$

Figure 13 shows the $p_{\mathrm{f}}$ that corresponds to increasing values of $\delta_{\text {Strength }}$, obtained for an FS of 1.5. As expected, the $p_{\mathrm{f}}$ increases with increasing uncertainty. This relationship may be used to determine the FS required for different values of $\delta_{\text {Strength }}^{\mathrm{Lab}}$, in order to reach the same $p_{\mathrm{f}}$. For example, if the value of $\delta_{\text {Strength }}^{\mathrm{Lab}}$ for Set 3 (0.13) gives a $p_{\mathrm{f}}$ of $2 \times 10^{-2}$ for an FS of 1.5 , the FS corresponding to this value of $p_{\mathrm{f}}$ will be lower for the situation in which there is a lower value of $\delta_{\text {Strength }}^{\mathrm{Lab}}$ of 0.02 (Set 1), but the FS corresponding to this value of $p_{\mathrm{f}}$ will be higher for the situation in which there is a higher value of $\delta_{\text {Strength }}^{\mathrm{Lab}}$ of 0.36 (Set 5). Specifically, Figure 13 shows that for a $\delta_{\text {Strength }}^{\mathrm{Lab}}$ of 0.02 (Set 1), a lower FS (1.22) allows the same $p_{\mathrm{f}}$ as that for Set 3. Similarly, for a $\delta_{\text {Strength }}^{\mathrm{Lab}} 0.36$ (Set 5), a higher FS (3.20) is required to reach the same $p_{\mathrm{f}}$ as that for Set 3. Consequently, a decrease in FS of 0.28 allows the same level of safety for a decrease in $\delta_{\text {Strength }}^{\mathrm{Lab}} 0.12$ (from Set 3 to Set 1). Also, an increase in safety factor of 1.70 is required for the same level of safety for an increase in $\delta_{\text {Strength }}^{\mathrm{Lab}}$ of 0.22 (from Set 3 to Set 5). The impact on the shear strength variability corresponding to variable conditioning procedures requires a higher FS to reach the same level of safety as Set 3 than typically used FS values.

Figure 14 shows similar information, obtained using the variability data from Sets 2, 4 and 6. In this situation, if the value of $\delta_{\text {Strength }}^{\mathrm{Lab}}$ for Set $4(0.12)$ gives a $p_{\mathrm{f}}$ of $9 \times 10^{-3}$ for an FS of 1.5 , the FS corresponding to this value of $p_{\mathrm{f}}$ will be lower for the situation in which there is a lower value of $\delta_{\text {Strength }}^{\mathrm{Lab}}$ of 0.05 (Set 2), but the FS corresponding to this value of $p_{\mathrm{f}}$ will be higher for the situation in which there is a higher value of $\delta_{\text {Strength }}^{\mathrm{Lab}}$ 0.16 (Set 6). Specifically, Figure 14 shows that for a $\delta_{\text {Strength }}^{\mathrm{Lab}} 0.05$ (Set 2), a lower FS (1.30) allows the same

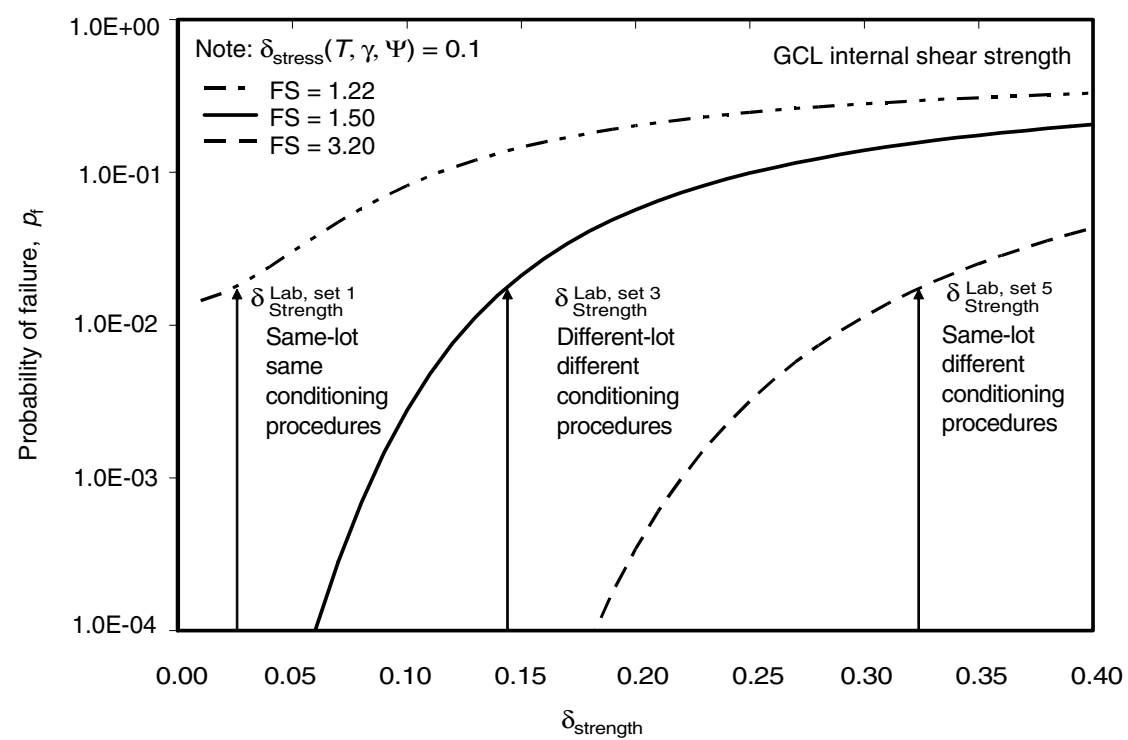

Figure 13. Required increase in safety factor to maintain same probability of failure with increasing GCL internal shear strength variability (Sets 1, 3 and 5) 


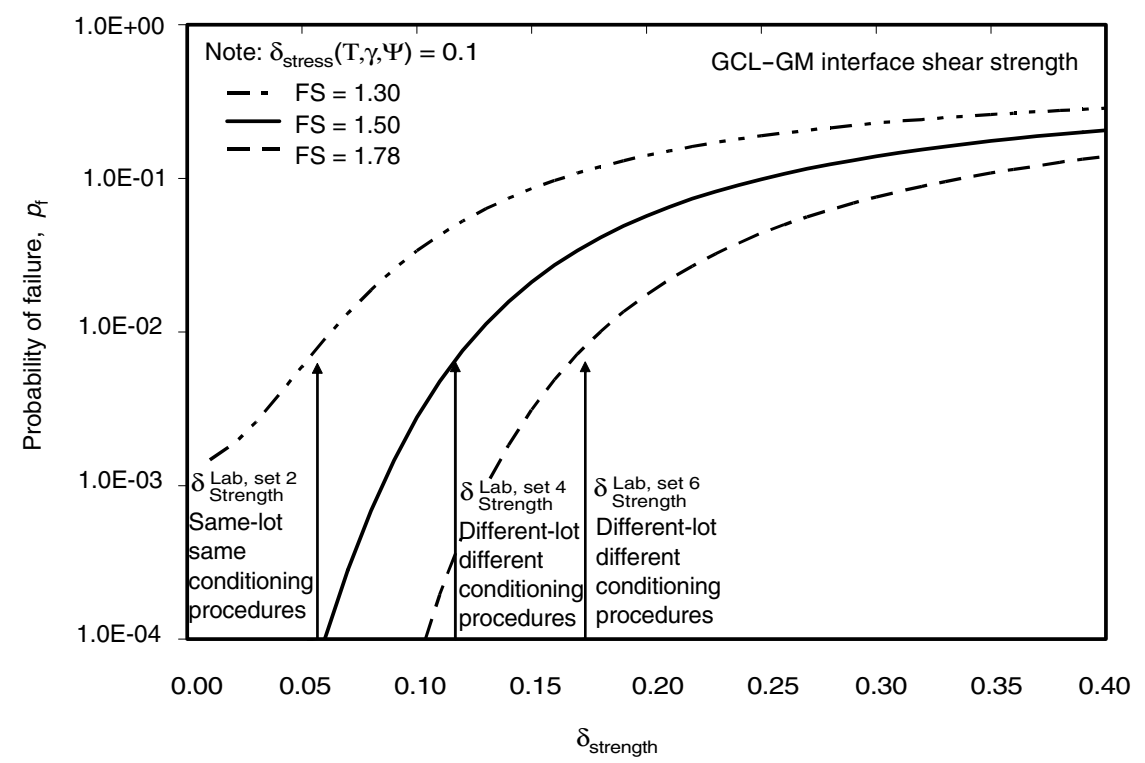

Figure 14. Required increase in safety factor to maintain same probability of failure with increasing GCL-GM interface shear strength variability (Sets 2, 4 and 6)

$p_{\mathrm{f}}$ as that for Set 4. Similarly, for a $\delta_{\text {Strength }}^{\mathrm{Lab}} 0.16$ (Set $6)$, a higher FS (1.78) is required to reach the same $p_{\mathrm{f}}$ as that for Set 4. Consequently, a decrease in FS of 0.20 allowed for the same level of safety for a decrease in $\delta_{\text {Strength }}^{\mathrm{Lab}}$ of 0.07 (from Set 4 to Set 2). Also, an increase in FS of 0.28 is required for the same level of safety for an increase in $\delta_{\text {Strength }}^{\mathrm{Lab}}$ of 0.04 (from Set 4 to Set 6).

The significant variability that is associated with product-specific shear strength data (obtained using GCL and GM products from different manufacturing lots with different conditioning procedures) leads to probabilities of failure that may be unacceptably high for FS values typically used in geotechnical practice. This emphasises the need to conduct shear strength testing programs to define project-specific shear strength values. The program should be conducted using specific conditioning procedures (i.e. variability noted in Sets 3 and 4). In summary, a conventional FS (e.g. FS = 1.5) may not constitute a good measure of the actual slope safety when using product-specific shear strength information of GCLs.

\section{CONCLUSIONS}

The implications of uncertainty in geosynthetic clay liner (GCL) shear strength are evaluated in this study. A recently compiled GCL internal and GCL-GM interface shear strength database provided a unique opportunity to characterize sources of uncertainty in GCL shear strength. The impact of shear strength variability arising from these different sources of uncertainty on the stability of GCL-lined systems was assessed using reliability-based methods. Further, a rational framework for testing programs in design and quality assurance programs was developed based on the different sources of uncertainty in shear strength.
A classification of different sources of uncertainty in GCL shear strength was developed. Use of this classification led to the following conclusions:

- Uncertainty in GCL shear strength arises from material variability within a single product type (intra-product) and between different product types (inter-product). Coefficients of variation in shear strength for intra-product shear strength ranged from approximately 0.02 to 0.35 , and coefficients of variation in shear strength for inter-product shear strength ranged from approximately 0.3 to 0.7 .

- For a given product type, uncertainty arises from material differences among specimens from the same manufacturing lot as well as among specimens from different manufacturing lots. The coefficient of variation in shear strength for same-lot specimens ranged from approximately 0.02 to 0.10 , whereas coefficients of variation in shear strength for different-lot specimens ranged from approximately 0.14 to 0.36 .

- In addition to material variability, uncertainty arises from differences in test procedures such as hydration, consolidation and shear displacement rate. The coefficient of variation in shear strength was found to increase from approximately 0.15 when test conditions were held constant to 0.35 when different test conditions are incorporated.

A framework was developed for quantifying the shear strength variability arising from different sources of uncertainty based on the number of project-specific tests developed. The following conclusions can be drawn:

- Project-specific testing was found to decrease the shear strength variability used in design. When no projectspecific testing is conducted, and shear strength values are obtained from product-specific databases, the coefficient of variation used in design is the same as that for inter-product variability $(0.4$ to 0.7$)$. How- 
ever, when project-specific testing is conducted, the coefficient of variation used in design decreases to approximately 0.05 to 0.1 for projects with a single manufacturing lot and to approximately 0.15 to 0.20 for projects using different manufacturing lots.

- For projects with a single manufacturing lot, the decrease in shear strength variability is inversely proportional to the square root of number of tests conducted, with little decrease beyond three tests. For projects with multiple manufacturing lots, the shear strength variability does not decrease significantly beyond a single test per each of the manufacturing lots.

Reliability-based stability analyses were used to assess the impact on conventional design methodologies of uncertainty in laboratory GCL shear strength test results. The following conclusions can be drawn:

- A higher FS than that typically used in geotechnical practice (1.5) was needed to ensure the same probability of failure when using shear strength variability from product-specific tests.

- For a cover veneer with a conventional FS greater than 3 for typical GCL internal shear strength parameters (conservative) and a conventional safety factor less than 1.25 for GCL-GM interface shear strength (unconservative), incorporating variability arising from different sources of uncertainty led to a significant increase in the probability of failure from approximately zero to $10^{-4}$ for internal failure and from approximately zero to $10^{-2}$ for interface failure.

- Positive correlation between $c$ and $\tan \phi$ was found to lead to a higher probability of failure for GCL internal shear strength, whereas negative correlation between $c$ and $\tan \phi$ was found to lead to a lower probability of failure for GCL-GM interface shear strength.

- When no project-specific testing is conducted, and shear strength values are obtained from product specific databases, the high associated uncertainty requires an FS used in design that is higher than typically used values. When project-specific testing is conducted, the corresponding decrease in uncertainty allows the FS used in design to be lowered, within typical ranges of FS values used in geotechnical practice.

- The penalty for not conducting project-specific testing and instead using product-specific data was found to be significant, owing to the high uncertainty in shear strength.

\section{ACKNOWLEDGEMENTS}

The writers thank SGI ${ }^{\circledR}$ Testing Services and GeoSyntec Consultants for making available the experimental results analysed in this study. The views expressed in this paper are solely those of the authors.

\section{NOTATIONS}

Basic SI units are given in parentheses.

$\begin{aligned} c & \text { GCL cohesion intercept }\left(\mathrm{N} / \mathrm{m}^{2}\right) \\ \text { FS } & \text { conventional safety factor (dimensionless) }\end{aligned}$
$\Delta \mathrm{FS}$ change in FS (dimensionless)

$p_{\mathrm{f}} \quad$ probability of failure (dimensionless)

$s_{X} \quad$ standard deviation of random variable $X$ (dimensions of $X$ )

SDR shear displacement rate $(\mathrm{m} / \mathrm{s})$

$t_{\mathrm{c}}$ time of consolidation (s)

$t_{\mathrm{h}}$ time of hydration (s)

$T$ veneer thickness $(\mathrm{m})$

$\beta$ reliability index (dimensionless)

$\delta_{X}$ coefficient of variation of variable $X$ (dimensionless)

$\gamma \quad$ veneer soil unit weight $\left(\mathrm{N} / \mathrm{m}^{3}\right)$

$\mu_{X}$ mean value of random variable $X$ (dimensions of $X$ )

$\rho(c, \tan \phi) \quad$ correlation coefficient between $c$ and $\phi$ (dimensionless)

$\sigma_{\mathrm{n}} \quad$ normal stress used during shearing $\left(\mathrm{N} / \mathrm{m}^{2}\right)$

$\tau_{\mathrm{p}}$ peak shear strength $\left(\mathrm{N} / \mathrm{m}^{2}\right)$

$\phi$ GCL friction angle $\left(^{\circ}\right)$

$\Phi$ standard normal cumulative density function (dimensionless)

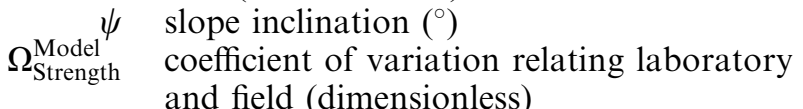

\section{APPENDIX A: FIRST-ORDER, SECOND MOMENT RELIABILITY METHODOLOGY}

This appendix presents the first-order, second moment reliability methodology used in Section 4.2. Further details may be obtained from Ang and Tang (1984), Duncan (2000) and Christian et al. (1994).

1. Define the mean safety factor $\mu_{\mathrm{FS}}$ for the infinite slope (Equation 2) using the mean value of each variable (slope inclination $\psi$, veneer thickness $T$, cover soil unit weight $\gamma$, and shear strength parameters $c$ and $\phi$ ).

2. Define the standard deviations of each random variable

3. Compute the safety factor with each variable increased by one standard deviation, $\mathrm{FS}_{i}^{+}$, and decreased by one standard deviation, $\mathrm{FS}_{\mathrm{i}}^{-}$, while keeping all remaining variables equal to their mean values. Find the difference between these two safety factors, $\Delta \mathrm{FS}_{\mathrm{i}}=\mathrm{FS}_{\mathrm{i}}^{+}-\mathrm{FS}_{\mathrm{i}}^{-}$. The standard deviation of the laboratory strength $s_{\text {Strength }}^{\mathrm{Lab}}$ is defined as follows:

$$
\begin{aligned}
& s_{\text {Strength }}^{\mathrm{Lab}}= \\
& \quad \sqrt{\left(\frac{\Delta F S_{c}}{2}\right)^{2}+\left(\frac{\Delta F S_{\phi}}{2}\right)^{2}+2 \rho(\tan \phi, c)\left(\frac{\Delta F S_{\tan \phi}}{2}\right)\left(\frac{\Delta F S_{c}}{2}\right)}
\end{aligned}
$$

where $\Delta \mathrm{FS}_{c}$ is the safety factor difference for the cohesion, $\Delta \mathrm{FS}_{\tan \phi}$ is the safety factor difference for the tangent of the friction angle, and $\rho(\tan \phi, c)$ is the correlation between $c$ and $\tan \phi$ defined as:

$\rho(\tan \phi, c)=\frac{\mu_{c \tan \phi}-\mu_{\tan \phi} \mu_{c}}{s_{\tan \phi} s_{c}}$ 
where $\mu_{c \tan \phi}$ is the mean value of the product of $\tan \phi$ and $c, \mu_{\tan \phi}$ and $\mu_{c}$ are the mean values of the probability distributions for $\tan \phi$ and $c$, and $s_{\tan \phi}$ and $s_{c}$ are the standard deviations of $\tan \phi$ and $c$. The correlation coefficient ranges from -1 to +1 , with a coefficient of 0 implying statistically independent random variables. A perfectly positive $(+1)$ or perfectly negative $(-1)$ coefficient implies that the data is linear with a positive or negative slope, respectively.

4. The standard deviation of the strength $s_{\text {Strength }}$ can then be found using the model uncertainty $\Omega_{\text {Strength }}^{\text {Mhodel }}$. The model uncertainty can be treated like another random variable with a mean value of 1.0 and a coefficient of variation of $\Omega_{\text {Strength }}^{\text {Model }}$. Thus, $s$ Strength is equal to $1.0 \times \Omega_{\text {Strength }}^{\text {Model }}$. Accordingly, $s_{\text {Strength }}$ can be defined as:

$$
s_{\text {Strength }}=\sqrt{s_{\text {Strength }}^{\text {Lab }}{ }^{2}+s_{\text {Strength }}^{\text {Model }}{ }^{2}}
$$

5. The standard deviation of the stress $s_{\text {Stress }}$ is then defined as follows:

$$
s_{\text {Stress }}=\sqrt{\left(\frac{\Delta F S_{\psi}}{2}\right)^{2}+\left(\frac{\Delta F S_{T}}{2}\right)^{2}+\left(\frac{\Delta F S_{\gamma}}{2}\right)^{2}}
$$

where $\Delta \mathrm{FS}_{\psi}$ is the safety factor difference for the slope inclination, $\Delta \mathrm{FS}_{T}$ is the safety factor difference for the veneer thickness, and $\Delta \mathrm{FS} \gamma$ is the safety factor difference for the soil unit weight.

6. The standard deviation of the safety factor $s_{\mathrm{FS}}$ is then defined as follows:

$$
s_{\mathrm{FS}}=\sqrt{s_{\text {Strength }^{2}+s_{\text {Stress }}^{2}}^{2}}
$$

7. Calculate the coefficient of variation of the safety factor, $\delta_{\mathrm{FS}}$, as:

$$
\delta_{\mathrm{FS}}=\frac{s_{\mathrm{FS}}}{\mathrm{FS}}
$$

8. The reliability index for a log-normally distributed safety factor $\left(\beta_{\mathrm{ln}}\right)$ can be calculated as follows (Ang and Tang 1984):

$$
\beta_{\ln }=\frac{\ln \left(\frac{\mathrm{FS}}{\sqrt{1+\delta_{\mathrm{FS}^{2}}}}\right)}{\sqrt{\ln \left(1+\delta_{\mathrm{FS}^{2}}\right)}}
$$

9. Calculate the probability of failure, $p_{f}$, using the calculated reliability index from Equation (4).

\section{REFERENCES}

Ang, A. \& Tang, W. (1975). Probability Concepts in Engineering Planning and Design, Volume I-Basic Principles, John Wiley \& Sons, New York, NY, USA.

Ang, A. \& Tang, W. (1984). Probability Concepts in Engineering Planning and Design, Volume II-Decision, Risk, and Reliability, John Wiley \& Sons, New York, NY, USA.

ASTM D 6243. Standard Test Method for Determining the Internal and Interface Shear Resistance of Geosynthetic Clay Liner by the Direct Shear Method, American Society for Testing and Materials, West Conshohocken, Pennsylvania, USA.

Bjerrum, L. (1973). Problems of soil mechanics and construction on soft clays. Proceedings of the 8th International Conference on Soil Mechanics and Foundation Engineering, Moscow, Vol. 3, pp. 111159.

Christian, J. T., Ladd, C. C. \& Baecher, G. B. (1994). Reliability applied to slope stability analysis. Journal of Geotechnical Engineering, 120, No. 12, 2180-2207.

Duncan, J. M. (2000). Factors of safety and reliability in geotechnical engineering. Journal of Geotechnical and Geoenvironmental Engineering, 126, No. 4, 307-316.

Gilbert, R. B. (2001). Peak versus residual strength for waste containment systems. Proceedings of the 15th GRI Conference on Hot Topics in Geosynthetics II (Peak/Residual; RECMs; Installation; Concerns), Austin, TX, USA, Geosynthetic Institute, 11PA, USA, pp. 29-39.

Gilbert, R. B., Wright, S. G. \& Leidtke, E. (1998). Uncertainty in back analysis of slopes: Kettleman Hills case history. Journal of Geotechnical and Geoenvironmental Engineering, 124, No. 12, 1167-1176.

Koerner, R. M. \& Koerner, G. R. (2001). Geosynthetics design beyond factor-of-safety; risk assessment using probability-of-failure analysis. Proceedings of the 15th GRI Conference on Hot Topics in Geosynthetics II (Peak/Residual; RECMs; Installation; Concerns), Austin, TX, USA, Geosynthetic Institute, 11PA, USA, pp. 235-253.

Liu, C. N., Gilbert, R. B., Thiel, R. S. \& Wright, S. G. (1997). What is an appropriate factor of safety for landfill cover slopes? Proceedings, Geosynthetics '97, IFAI, Roseville, MN, pp. 481-496.

McCartney, J., Zornberg, J. \& Swan, R. Jr (2002a). Internal and Interface Shear Strength of Geosynthetic Clay Liners (GCLs), Geotechnical Research Report, University of Colorado at Boulder, Department of Civil, Environmental and Architectural Engineering, Boulder, CO, USA, $471 \mathrm{pp}$.

McCartney, J., Zornberg, J. \& Swan, R. Jr (2002b). Internal and Interface Shear Strength of Geosynthetic Clay Liners (GCLs): Additional Data, Geotechnical Research Report, University of Colorado at Boulder, Department of Civil, Environmental and Architectural Engineering, Boulder, CO, USA, 36 pp.

Sabatini, P. J., Griffin, L. M., Bonaparte, R., Espinoza, R. D. \& Giroud, J. P. (2002). Reliability of state-of-practice for selection of shear strength parameters for waste containment system stability analyses. Geotextiles and Geomembranes, 20, 241-262.

Skempton, A. (1985). Residual strength of clays in landslides, folded strata and the laboratory. Géotechnique, 35, No. 1, 3-18.

Terzaghi, K., Peck R.B. \& Mesri G. (1996). Soil Mechanics in Engineering Practice. John Wiley \& Sons, New York, NY, USA.

Thiel, R. (2001). Peak vs. residual shear strength for bottom liner stability analyses. Proceedings of the 15th GRI Conference on Hot Topics in Geosynthetics II (Peak/Residual; RECMs; Installation; Concerns), Geosynthetic Institute, 11Pennsylvania, USA, pp. 40-70.

Zornberg, J. G., Sitar, N. \& Mitchell, J. K. (1998). Limit equilibrium as a basis for design of geosynthetic reinforced slopes. Journal of Geotechnical and Geoenvironmental Engineering, 124, No. 8, 684698. 